\title{
ASPECTOS GEOLÓGICOS DE LAS ROCAS METAVOLCÁNICAS Y METASEDIMENTARIAS DEL GRUPO LAVALLEJA, SUDESTE DE URUGUAY
}

\author{
LEDA SÁ NCHEZ BETTUCCI* \& VÍCTOR A. RAMOS**
}

\begin{abstract}
GEOLOGIC ASPECTS OF METAVOLCANIC AND METASEDIMENTARY ROCKS OF THE LAVALLEJA GROUP, SOUTHEASTERN URUGUAY The Lavalleja Group consists on a volcanic-sedimentary sequence, lithologically represented by metapelites, metapsamites, metashales and by interestratified acidic and basic metavolcanic rocks. The Lavalleja Group presents a Ryocke-Abukuma-like metamorphism, varying from very low grade in the northwest to low amphibolite facies in the southeast; it has a northeast trend, showing an important shortening with western vergence. To the east, the Carapé Complex tectonically bound it. The western limit consists on an intrusive-like contact with the alkalic volcanic-subvolcanic Sierra de Las Animas Complex. The Lavalleja Group is part of the Dom Feliciano Belt. The Lavalleja Group can be divided in Minas, Fuente del Puma and Zanja del Tigre Formations.

Keywords: Lavalleja Group, Ryocke-Abukuma metamorphism, Neoproterozoic, back-arc basis, Uruguay.

RESUMEN El Grupo de Lavalleja está representado por una sucesión volcano-sedimentaria, constituido biológicamente por metapelitas, metapsamitas, metacalcáreos y por rocas metavolcanicas acidas y básicas interestratificadas. El Grupo Lavalleja se encuentra afectado por un metamorfismo de tipo Ryocke-Abukuma, variando desde muy bajo grado, en el noroeste hasta facies anfibolita superior en el sudeste. Este grupo presenta una dirección general noreste y un acortamiento importante en sentido sudeste-noroeste, con vergencia occidental. Al este, se encuentra en contacto tectónico con el Complejo Carapé mientras que el límite occidental esta dado por un contacto de tipo intrusivo con el Complejo Sierra del Las Animas. El Grupo Lavalleja, parte del Cinturón Dom Feliciano, es separado en tres formaciones: Minas, Fuente del Puma y Zanja del Tigre.

Palabras-llaves: Grupo Lavalleja, metamorfismo Ryocke-Abukuma, Neproterozoico, bacia back-arc, Uruguay.
\end{abstract}

INTRODUCCIÓN El Grupo Lavalleja consiste en una secuencia volcano sedimentaria desarrollada en dirección noreste que presenta un importante acortamiento en sentido este-sudeste. Este grupo comprende litologías muy variadas, desde importantes paquetes metasedimentarios tales como metapelitas, metapsamitas, metalimolitas, metacalizas; paquetes metavolcánicos ácidos representados por hialoclastitas, metariolitas y metadacitas; metavolcanitas básicas constituidas por metandesitas, metabasaltos vesiculares y macizos, metabasaltos, metandesitas basálticas y brechas espillíticas, metagabros y metadoleritas. Las litologías más abundantes corresponden a rocas metabásicas, metapelitas y calcáreos. Se incluye dentro del Grupo Lavalleja a las litologías orto y para derivadas que presentan un grado medio de metamorfismo asignadas anteriormente al Grupo Carapé (Bossi 1989, Bossi \& Navarro 1991) y que es redenominado Complejo Carapé (Sánchez Bettucci 1998). El Complejo Carapé quedaría representado exclusivamente, por granitos, granodioritas, granitos protomiloníticos y miloníticos, gneisses orto derivados y migmatitas, que afloran en contacto tectónico con el grupo Lavalleja, y que ocasionalmente ocurren como escamas tectónicas, dentro de éste y las cuales han sido denominadas como faja granítica central o complejo gnéissico-migmatítico (Preciozzi et al. 1985).

Importantes aportes al conocimiento del Grupo Lavalleja fueron brindados por Midot (1984). Este autor describió brechas volcánicas próximas al castillo de Batlle y de la estancia La Salvaje dentro de una estructura sinclinoria. Este autor separó al Grupo Lavalleja en dos series, que consideró sincrónicas con pasaje lateral por variaciones de facies de una a otra: la serie metasedimentaria de Minas, constituida por cuarcitas y calizas aflorantes en las proximidades de la ciudad homónima y por otro lado a la serie metavolcanosedimentaria de Fuente del Puma, que aflora al sur de la ciudad de Minas asociado a un volcanismo básico con tendencia espillítica y de carácter calcoalcalino a tholeítico. Preciozzi (1989a, b, c y d) realizó una síntesis estructural, litoestratigráfica y metalogenética de la serie metavolcanosedimentaria, similar a la efectuada por Midot (1984). Posteriormente, Bossi \& Navarro (1991) separaron por un lado al Grupo Lavalleja y por otro lado al Grupo Rocha, argumentando que la naturaleza litológica es netamente diferente, aunque sean parcialmente sincrónicas. Asimismo, postularon un metamorfismo en grado bajo para el Grupo Lavalleja. Son muy numerosas las descripciones litológicas realizadas desde Walther (1919) a Preciozzi et al. (1993) pero a nivel de estructura, separación de unidades siguiendo un criterio geológico, son escasas y contradictorias.

El objetivo del presente trabajo es analizar la geología de la región Minas-Piriápolis (Fig. 1) desde el punto de vista petrográfico, estructural y geocronológico. Esto implica tratar de resolver la estratigrafía del Grupo y reconstruir las relaciones espaciales de las diferentes unidades.

GEOLOGÍA DEL GRUPO LAVALLEJA El Grupo Lavalleja está caracterizado por la presencia de angostas fajas de rocas metasedi- mentarias y metavolcanicas que han sido intensamente deformadas y que han sido separadas en tres grandes unidades en función de las asociaciones litológicas y del grado metamórfico (Sánchez Bettucci 1998). La primera - Formación Minas -incluye litologías afectadas por anquimetamorfismo a un metamorfismo en grado muy bajo; la segunda - Formación Fuente del Puma - se encuentra caracterizado por un metamorfismo en grado bajo a facies de esquistos verdes inferior y está representada por litologías variadas que fueron agrupadas como: un miembro sedimentario, otro volcánico y otro formado por meta gabros hornbléndicos. El miembro sedimentario está representado por metacalizas, metacalcopelitas, metapelitas y metaarcosas. Dentro de éste se encuentra intercalada una unidad volcánica con términos ácidos y básicos. Esta última se encuentra caracterizada por la ocurrencia de metabasaltos macizos y vesiculares, metandesitas, metariolitas, metadacitas, ignimbritas e hialoclastitas. Los gabros hornbléndicos, aparecen mejor desarrollados al este de los dos miembros anteriores y se encuentran caracterizados por cuerpos elongados. Dentro de la unidad de esquistos micáceos se incluyen mármoles, esquistos biotíticos, esquistos cloríticos, tremolíticos y anfibolitas. Esta unidad está desarrollada al este de la unidad de gabros hornbléndicos.

Por último, la tercer unidad -Formación Zanja del Tigre-incluye litologías con facies metamórficos esquistos verdes superior en transición a facies de anfibolita inferior y facies anfibolita superior. Esta incluye a esquistos micáceos, mármoles y anfibolitas.

El Grupo Lavalleja presenta un metamorfismo de tipo regional de baja a moderada presión, que varía desde muy bajo grado, en el oeste-noroeste, a facies de anfibolita superior, hacia el este-sudeste. Hacia el oeste se encuentra en contacto intrusivo con el complejo sierra de las Animas, mientras que hacia el este se halla en contacto tectónico con el Complejo Carapé. Las relaciones estratigráficas de las diferentes unidades analizadas puese observarse en la tabla 1.

El Grupo Lavalleja forma parte del Cinturón Dom Feliciano definido por Fragoso Cesar (1980) y que fuera denominado por Preciozzi et al. (1991) como Cinturón Cuchilla de Dionisio en la porción uruguaya. Bossi \& Campal (1992) mantuvieron esta denominación para la faja móvil brasiliana en el Uruguay. Asimismo, cabe destacar los trabajos de Fernandes et al. (1992,1993,1995a,b), Fragoso Cesar (1991,1993,1995), Fragoso Cesar \& Machado (1997), Fragoso Cesar et al. (1998), Hartmann et al. (1998), entre otros, donde se proponen modelos sobre la base de las asociaciones petrotectónicas encontradas en Brasil y Sudáfrica y, por lo tanto se ajustan parcialmente a las unidades aflorantes en el sudeste de Uruguay.

El Cinturón Dom Feliciano presenta una estructuración regional nor-noreste en donde se destacan importantes fallas de rumbo con la misma orientación (Fig. 2). Este incluye de oeste a este al Grupo Lavalleja, el Complejo Carapé, la faja granítica central, la Formación Rocha y al Grupo Aiguá-Parallé.

Formación Minas (Mac Millan 1933, enmendado por Midot 1984) Esta unidad se encuentra localizada en las proximidades

Facultad de Ciencias, Instituto de Geología y Paleontología, Depto. de Geología. Iguá 4225, CP:11400, E-mail: leda@fcien.edu.uy

Facultad de Ciencias Exactas y Naturales, Departamento de Ciencias Geológicas, Laboratorio de Tectónica Andina, Pabellón II, Nuñez, Buenos Aires,

Argentina.E-mail:andes@gl.fcen.uba.ar 

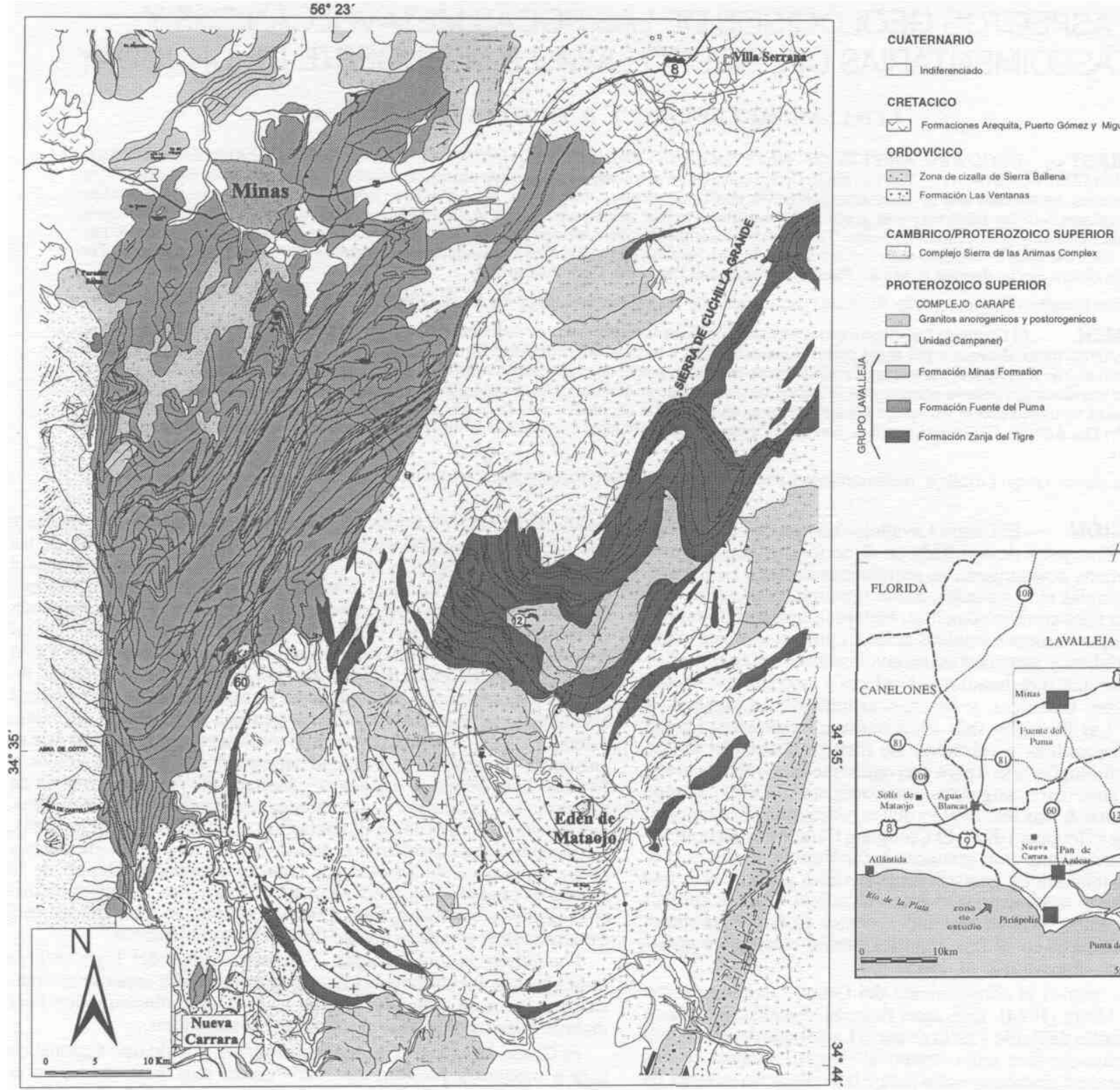

Figura 1 - Mapa de localización y mapa geológico de la región estudiada.

de la ciudad de Minas, y esta representada por areniscas conglomerádicas, arcosas, cuarcitas, pelitas y rocas carbonáticas (Fig. 1). Esta unidad es tratada en forma separada dado que, aunque se presentan en continuidad con el resto de las litologías del Grupo Lavalleja; presentan muy poca deformación y varían desde anquimetamórficas a un bajo grado de metamorfismo. Estas litologías corresponderían a lo que Midot (1984) definió como Serie de Minas, encontrándose aflorando en los alrededores de la ciudad de Minas. Este autor dividió a esta unidad en dos subtipos, el primero, localizado al noroeste de la hoja Fuente del puma, caracterizado por una alternancia de bancos calcáreos y dolomíticos de coloraciones grisáceas con intercalaciones de pelitas; mientras que el segundo, al norte de la ciudad de Minas, esta constituido por cuarcitas -equivalentes a aquellas que se encuentran aflorando en el cerro Verdún (Formación Salus de Chiron 1982)- y calcáreos con coloraciones castaño claro con intercalaciones de psamitas con coloraciones ocres. El conjunto litológico precedente es elevado al rango de formación.

Uno de los representantes más conspicuos corresponde a cuarcitas magnetíticas, tales como aquellas que afloran en el cerro Negro. Por debajo de este nivel afloran conglomerados matriz soportados. Presentan un basculamiento de $40-50^{\circ}$ al norte. Hacia el tope de esta unidad continúa una sucesión de pelitas masivas, pelitas suavemente bandeadas, arcosas de grano medio a fino, pelitas bandeadas con interca- laciones milimétricas de hematita, areniscas conglomerádicas con estratificación en artesa, arcosas gruesas, areniscas con estratificación entrecruzada de bajo ángulo, pelitas con laminación plano paralela, calizas estromatolíticas, brechas estromatolíticas, calcáreos finamente laminados y finalmente pelitas con coloraciones borra de vino con laminación plano paralela. Este último nivel presenta granos de cuarzo dispersos de hasta dos milímetros y pelitas y psamitas finas con niveles hematíticos intercalados.

En el perfil levantado de ésta unidad (Fig. 3) se observa que los paquetes presentan una potencia promedio de 8 metros. El límite entre las carnadas suele ser de tipo erosivo y en general las coloraciones son rosadas a grises negruzcas. En estas unidades se observa tanto en muestra de mano como en cortes petrográficos una importante cantidad de minerales opacos -hematita- lo que le otorga a las rocas coloraciones borra de vino. Las psamitas finas masivas están constituidas mineralógicamente por granos de cuarzo subredondeados y subordinadamente feldespatos y opacos. La matriz es arcillosa, presentando óxidos de hierro. Las psamitas finas con niveles hematíticos tienen la misma mineralogía. La diferencia radica en la laminación milimétrica y por los niveles de hematita que no superan los 2 milímetros. Las arcosas están constituidas por cuarzo y feldespato, subordinadamente plagioclasa. Presentan coloraciones blanquecinas y los granos son subangulosos. En el cerro del Negro, al sur del cerro Caperucita afloran de base 
a techo niveles de brechas, conglomerádicos con una potencia aparente de 20 metros, bancos de poca potencia ( 2 metros) de cuarcitas y de niveles ferríferos (banded iron formation) que no superan los 10 metros de espesor. Por encima de este último banco ocurren pelitas finamente laminadas ricas en óxidos de hierro. Los límites entre cada nivel son de tipo erosivos. Esta formación no presenta intercalaciones de rocas volcánicas, tal como ocurre en la Formación Fuente del Puma.

Tabla 1 - Relaciones estratigraficas de las diferentes unidades aflorantes.en el sudeste de Uruguay.

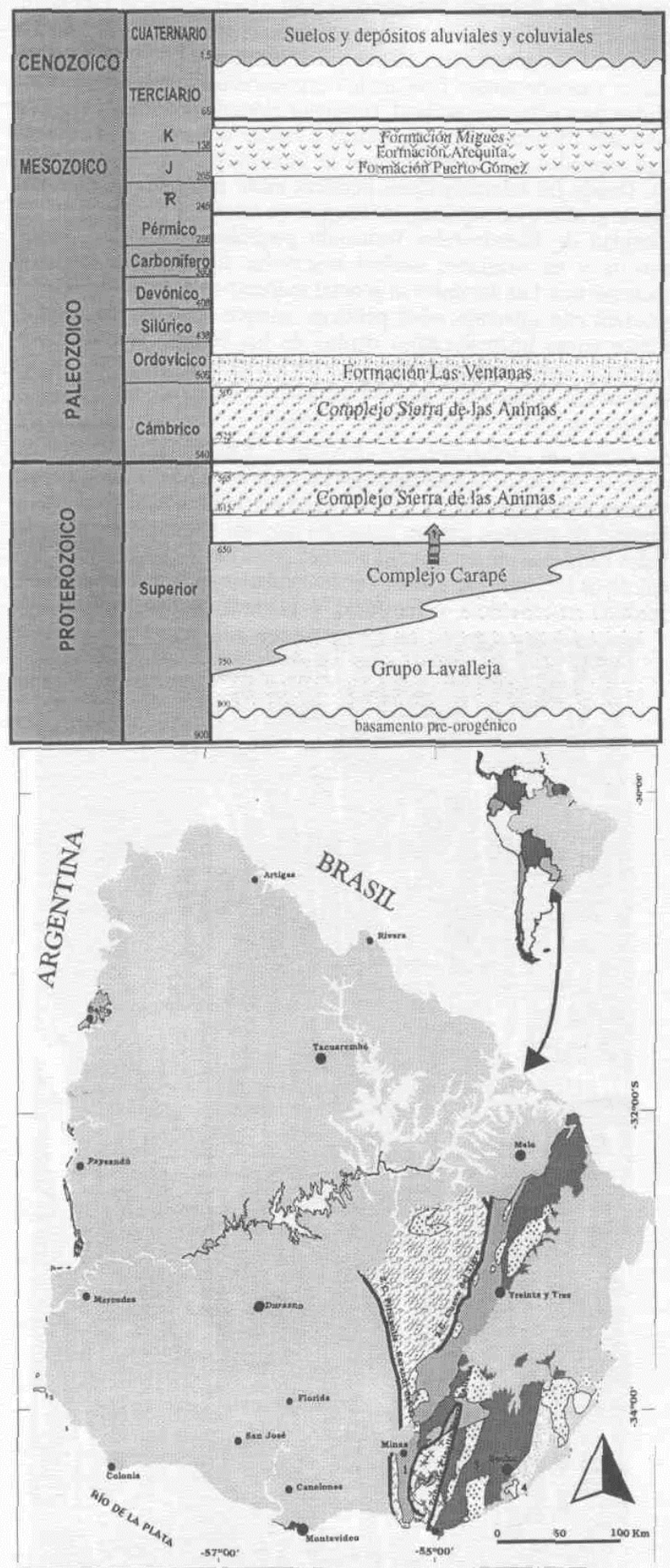

Figura 2 - Esbozo geológico del cinturón Dom Feliciano mostrando las diferentes unidades para el sudeste de Uruguay (1: Grupo Lavalleja, 2: Complejo Carapé, 3: zona granítica central, 4: Formación Rocha)
Esta unidad se encuentra recortada por filones riolíticos de la Formación Arequita.

En el tope de esta unidad afloran calizas masivas, estromatolíticas, brechosas (brechas intraformacionales) y laminadas (Fig. 4). Estas se encuentran escasamente expuestas en la ladera sur del cerro Arequita y en la ladera oriental del cerro Caperucita. Los afloramientos localizados en la ladera sur del cerro Arequita se encuentran afectados por metamorfismo de contacto. Presentan comúnmente colores claros a grises. Los niveles con estructuras estromatolíticas no exceden nunca los 50 centímetros. Por encima de este nivel se reconoce una laminación plano paralela, mientras que por debajo ocurre un nivel de margas finamente laminadas y niveles brechosos. Aquellas brechas calcáreas localizadas en la ladera sur del cerro Arequita están constituidas fundamentalmente por intraclastos de calcáreos macizos y estromatolíticos. Siguiendo la clasificación de Logan et al. (1964) los estromatolitos que ocurren en la ladera oriental del cerro Caperucita corresponderían al tipo LLH-C. Son de tipo hemisferoides unidos lateralmente, espaciados (LL-S), donde las láminas presentan una estructura estromatolítica correspondiente al subtipo LLH-C.

Unidades litológicas semejantes a las descriptas han sido agrupadas bajo la denominación de Formación Cerro Espuelitas han sido descriptas por Gaucher et al. (1996). Esta unidad se encuentra localizada aproximadamente 30 kilómetros al norte de la ciudad de Minas y esta conformada de base a tope por pizarras negras, rocas carbonáticas, BIF y chert. Estos autores sugirieron una sedimentación en ambientes de plataforma por debajo del nivel de base de tormentas. La edad de la misma fue asignada por estos autores sobre la base de la presencia de microfósiles determinados por Gaucher \& Sprechmann (1995) y Gaucher et al. (1996) tales como Bavlinella faveolata, L Bicrura, Lophosphaeridiwn sp. A. Symplossosphaeridium sp., Oscillatoriopsis rhomboidalis, Leiothrichoides typicus, Soldadophycus bossii y Leiothrichoides sp., sugiriendo una edad vendiana superior.

Estudios palinológicos llevados a cabo sobre 12 muestras representativas de los niveles pelíticos y ferríferos del cerro del Negro no revelaron la presencia de microfósiles, aunque fue reconocido (com. Pers. Dr. Ottone) a través de un corte petrográfico la presencia de bacterias de tipo filamentosas (Fig. 5).

Formación Fuente del Puma (Midot 1984) Esta unidad se encuentra desarrollada, en la zona bajo estudio, al sur de la ciudad de Minas hasta la ciudad de Pan de Azúcar. Se encuentra limitada al oeste por el Complejo Sierra de Animas y al este por los corrimientos La Oriental, al sur y Pan de Azúcar (Fig. I). Las distintas unidades litológicas reconocidas son separadas en tres miembros distintos: el sedimentario, el volcánico y los gabros hornbléndicos, a los que se le agrega el prefijo meta dado que el protolito es claramente reconocible. La Formación Fuente del Puma presenta un metamorfismo en grado

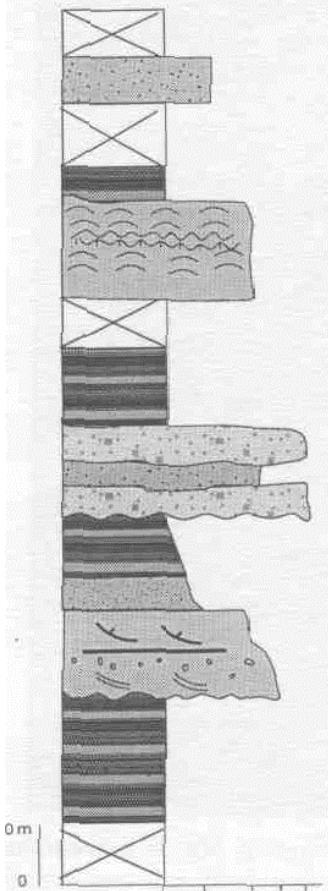

estratificación entrecruzada en artesa

estratificación cruzada de bajo ángulo

calizas estromatoliticas

calizas laminadas y masivas
F: pelitas, Pmf: psamitas muy finas, Pf: psamitas finas, Pm: psamitas medias, P.G: psamitas conglomerádicas

Figura 3 - Perfil estratigráfico de la Formación Minas. 
facies esquistos verdes inferior (zona de clorita) a superior (zona de granate) Esta unidad fue definida como Serie Fuente del Puma por Midot (1984) y aquí elevada al rango de Formación. Miembro sedimentario Dentro del miembro sedimentario ocurren las siguientes litologías, las cuales son agrupadas en facies carbonáticas, silicoclásticas y calcoclásticas.

FACIES CARBONÁTICAS Existen desde Walther (1912) numerosos estudios sobre los calcáreos de la región dada su importancia en la explotación como materia prima (e.g. cantera del cerro Verdún, mina La Plata, cantera Burgeño). Un análisis de esos resultados muestra que los tenores de carbonato de calcio suelen ser variables de banco a banco. Este autor fue el primero en clasificar la secuencia carbonática -a partir de los rasgos tanto macroscópicos como microscópicos- en cinco grupos: a) con estructura densa, b) con grano cristalino fino, c) de textura sacaroide, d) de grano grueso y e) de grano muy grueso. Marstrander (1914) citó la ocurrencia de dolomitas puras que localmente presentan tremolita, Walther (1919) efectuó, a partir de su primera clasificación, un trabajo de mayor precisión en la clasificación de las calizas y mármoles calcíticos y dolomíticos, además de considerar como epizonales a las primeras y como mesozonales a los segundos; mientras que los mármoles con cristales mayores a los cinco milímetros los consideró catazonales. Asimismo, tal como lo sugirió Midot (1984) las rocas carbonáticas pasan gradualmente a bancos dolomíticos bastante puros, aunque los niveles de calizas dolomíticas son los más abundantes.

Litofacies de metacalizas, metacalizas macizas, metacalizas dolomíticas y metadolomitas Los niveles más importantes de dolomías y calizas dolomíticas se encuentran localizados al sur de la ciudad de Minas, en las proximidades de Mina Valencia, donde se explotó un nivel dolomítico en donde el porcentaje de $\mathrm{CaCO}_{3}+\mathrm{MgCO}_{3}$ es de un $99.94 \%$. Localmente se han observado intercalaciones de metavolcanitas acidas y de metapelitas sericíticas. En esta litofacies se incluyen calizas puras y calizas dolomíticas. Los paquetes más potentes corresponden generalmente a calizas que gradan a calcopelitas y a calizas dolomíticas. Estas presentan, algunas veces, una laminación

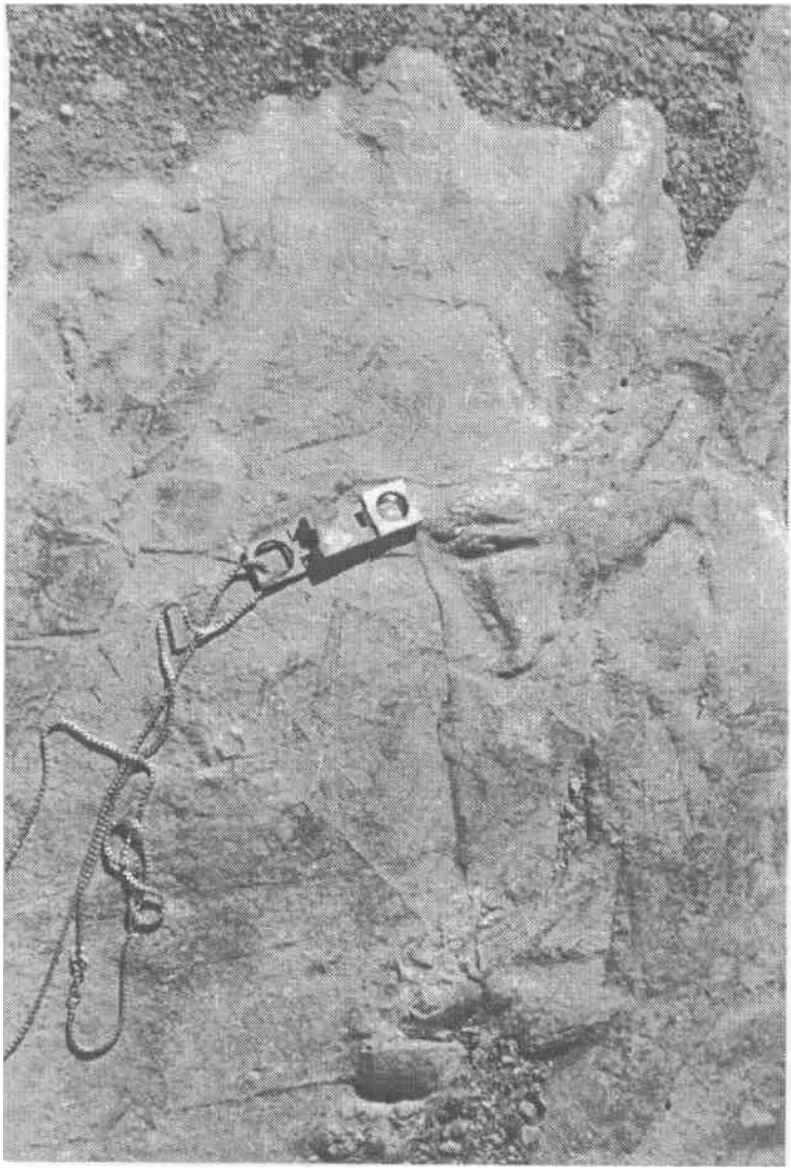

Figura 4 - Nivel de calizas de la Formación Minas presentando intraclastos calcáreos donde se destacan fragmentos de estromatolitos. original mientras que lo más común es que presenten foliación metamórfica. En muchos casos los niveles de calizas presentan intercalaciones de calcopelitas tal como ocurre en las canteras de COMSA, localizada próxima a la Laguna del Sauce, Burgeño o bien se encuentran como intercalaciones en bancos dolomíticos (ruta nacional 12). Los calcáreos macizos constituyen importantes cuerpos elongados de dimensiones kilométricas y como lentes discontinuos asociados tanto a metapelitas como a rocas volcánicas básicas, en la mayoría de los casos. Se han reconocido algunas estructuras internas, tales como laminación plano paralela y estratificación entrecruzada, aunque en la mayoría de los sitios analizados se encuentra afectada por foliación metamórfica. Presentan coloraciones blancas a grises claras, raramente coloraciones anaranjadas a ocres indicando la presencia de hematita $o$ limolita. En algunos casos es notorio un bandeado composicional de mayor y menor pureza. Esta unidad es generalmente objeto de extracciones para cemento portland, como por ejemplo la mina La Plata de ANCAP. Muchos bancos de calizas y calizas dolomíticas se encuentran afectados por cabalgamientos de granitos protomiloníticos (Fig. 6). Donde las intercalaciones pelíticas están presentes, o en zonas donde gradan a calcopelitas, los cuerpos de calcáreos presentan mayor cantidad de filominerales formando pequeñas bandas de clorita, sericita y en ocasiones anfíbol orientadas siguiendo la foliación metamórfica. Las dolomías en general aparecen en general en paquetes macizos con intercalaciones pelíticas, aunque ocurren más comúnmente como intercalaciones dentro de las calizas. Las calizas y dolomías están caracterizadas petrográficamente por cristales en mosaico de calcita y dolomía, presentando en forma accesoria algunos cristales de clorita, sericita opacos y cuarzo.

Litofacies de metabrechas calcáreas Esta litofacies ha sido reconocida al este de la ruta nacional 12, entre la zanja del Tigre y el río Carapé. Esta se encuentra caracterizada por la presencia de clastos y bloques de granitos, gabros, como así también intraclastos calcáreos. Estos calcáreos presentan coloraciones grisáceas y blanquecinas. Los calcáreos brechosos se encuentran intercalados entre areniscas finas a medias, muscovíticas y fucsíticas y granitos protomiloníticos. La

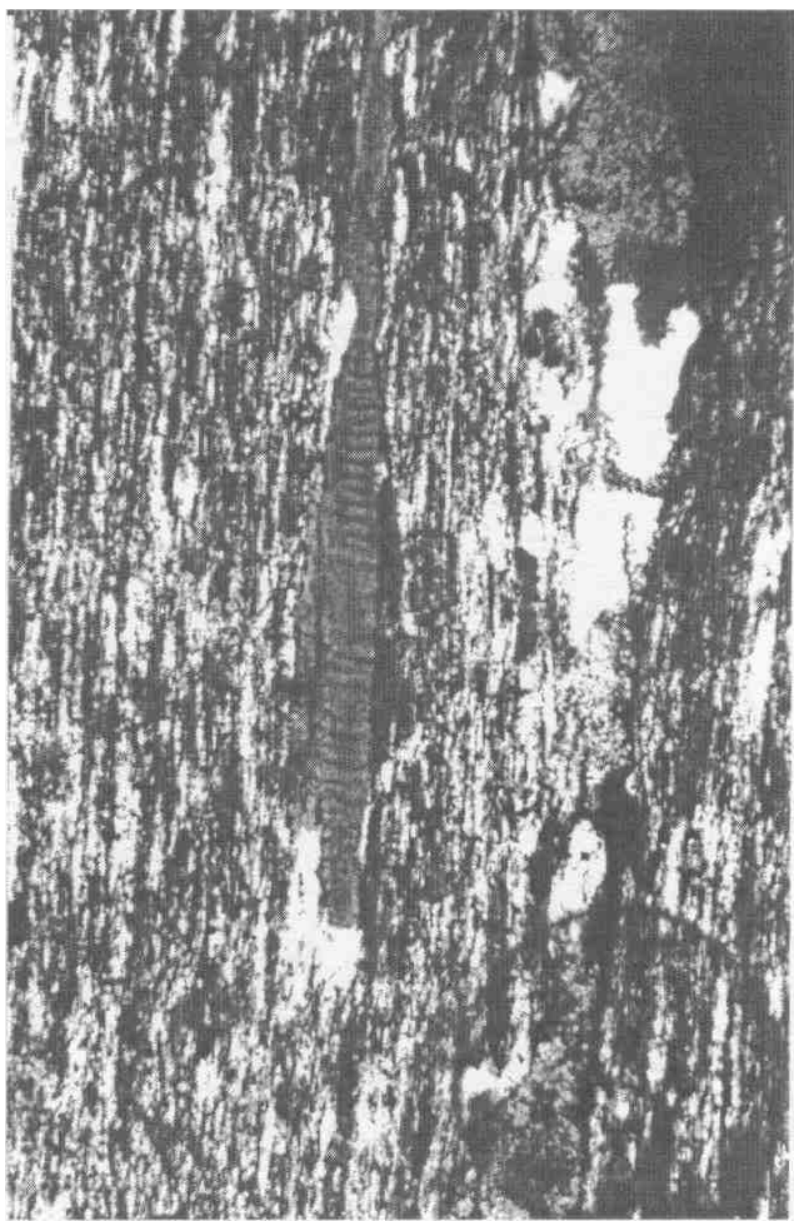

Figura 5 - Fotomicrografias de una metapelita donde se observa una bacteria de tipo filamentosa (Formación Minas). 


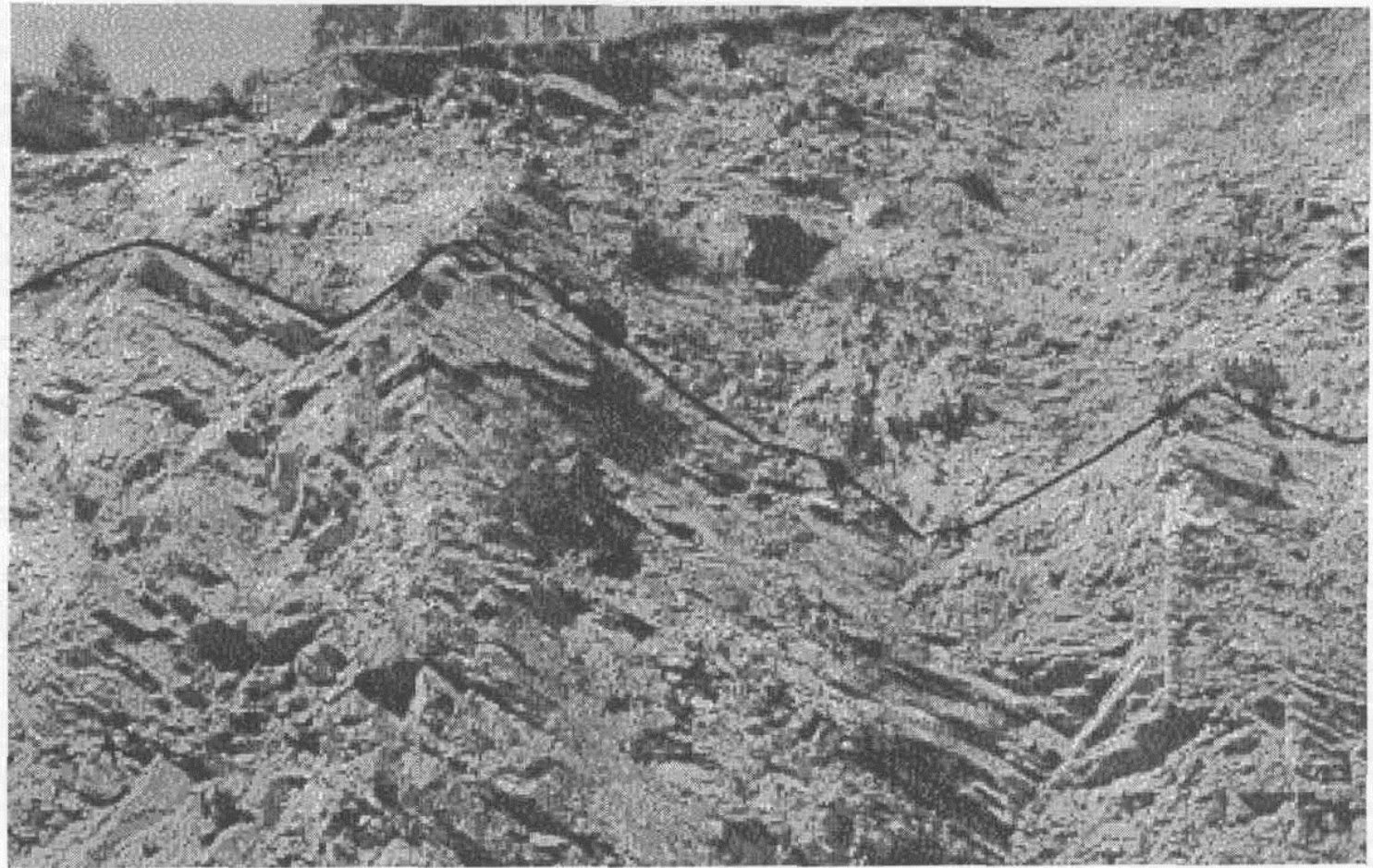

Figura 6 - Metacalizas cabalgadas por granitos protomiloníticos del Complejo Carapé.

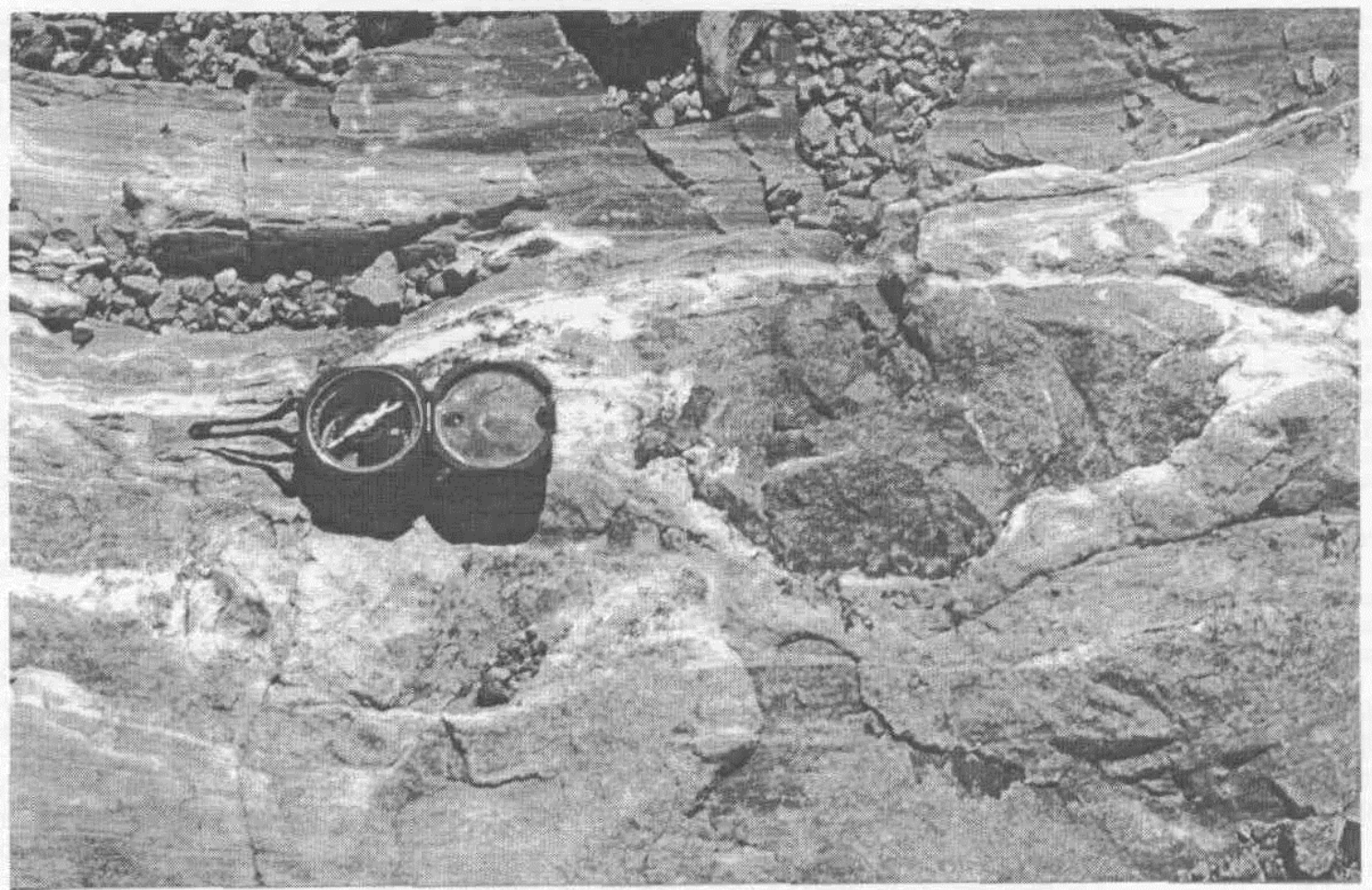

Figura 7 - Detalle de niveles metacalcáreos presentando bloques de gabros, granitos e itraclastos, perturbando la laminación original.

característica de algunos niveles es la presencia dentro de ellos de una importante cantidad de intraclastos, clastos de metagabros y granitos. El tamaño promedio oscila desde 20 centímetros al metro (Fig. 7), mientras que la potencia de esta unidad es de aproximadamente 200 metros. Asimismo, existen carnadas caracterizadas por presentar intraclastos, clastos de cuarcitas y de granitos de hasta $8 \mathrm{~cm}$. La potencia máxima de éstas nunca supera los 2 metros y se encuentra intercalada entre calcáreos macizos y finamente laminados. En estos niveles no se observaron clastos o bloques de gabro.

Los indicadores de polaridad de capas indican, tal como se encuentra hoy la secuencia, que la base de la misma estaría hacia el oeste. Estas protuberancias (estructuras de carga) son de forma irregular y sobresalen de los estratos con la convexidad hacia la parte inferior. Estos niveles podrían estar indicando que durante la sedimentación de estos importantes niveles carbónaticos ocurrieron importantes cambios climáticos asignado a los efectos tardíos de la glaciación Verangeriana o bien ser el resultado de una etapa de importante inestabilidad gravitacional y tectónica, considerando a la primera como la más factible dado que este fenómeno resulta ser bastante local.

Litofacies de metacalizas estromatolíticas En esta litofacies se incluyen aquellos afloramientos aislados donde se han reconocido posibles estructuras estromatolíticas intercaladas en calizas laminadas, tales como aquellas que aparecen al sudoeste del cerro Redondo. Los 
estromatolitos que ocurren próximos al cerro Redondo corresponden, siguiendo la clasificación de Logan et al. (1964), al tipo LLH-S. Son de tipo hemisferoides unidos lateralmente, espaciados (LL-S), donde las láminas presentan una estructura estromatolítica correspondiente al subtipo LLH-C. Estas estructuras estromatolíticas son típicas de ambiente litoral y en particular se desarrollan en lugares protegidos de zonas intermareales, donde la agitación de las aguas es débil,

FACÍES SILICOCLÁSTICA La facies silicoclástíca es separada en distintas litofacies:

Litofacies de metapelitas Se presentan con colores castaños, verdosos y gris obscuro; se encuentran comúnmente intercaladas con rocas metavolcánicas, metacalcopelitas y metalimolitas de colores ocres. Esta litología está caracterizada por sus paquetes bastante potentes y que normalmente gradan ya sea metalimolitas o bien a metacalcopelitas. Se hallan mejor expuestas al oeste de la Formación las Ventanas, en el sur, hasta el corrimiento tres cerros, que constituye el límite nor - nororiental; además de aflorar como intercalaciones en el resto de la sucesión sedimentaria. La potencia de estos paquetes metapelíticos alcanza los $2.000 \mathrm{~m}$. Esta unidad suele presentar intercalaciones milimétricas a centimétricas de metapsamitas finas y finas a medias con gradación. Las metapelitas constituyen generalmente bancos tabulares de importante continuidad lateral. Las estructuras sedimentarias reconocidas son laminación plano paralela y gradación. Los contactos suelen ser concordantes y erosivos. En algunos casos aparecen sobre los planos de estratificación pequeños niveles piritosos, donde los cristales pueden alcanzar el centímetro. En la mayoría de los casos la laminación original es paralela a la foliación metamórfica. Se han reconocido pequeños niveles de metapelitas carbonosas. Esta litología presenta coloraciones gris-negruzca con abundantes pátinas de óxidos de hierro. Las metalimolitas, incluidas en esta litofacies, presentan comúnmente un $85 \%$ de cuarzo en agregados granoblásticos y un $5 \%$ de plagioclasas. La matriz esta constituida por pequeños cristales de clorita, sericita orientada y epidoto. En función del componente mineral característico fue posible separar cinco tipos de metapelitas diferentes, a saber: sericíticas, cuarzosas, piritosas, magnetíticas y carbonosas. Las primeras tres afloran intercaladas indistintamente en la comarca, mientras que las metapelitas magnetíticas se las ha encontrado aflorando únicamente a $100 \mathrm{~m}$ al norte de la estancia La Salvaje y las metapelitas carbonosas al pie del cerro Redondo o del Esmeril, localizado al sudoeste de la ciudad de Minas.

Petrográficamnte las metapelitas presentan textura lepidoblástica, donde la sericita representa el constituyente esencial. Son comunes las intercalaciones milimétricas de agregados granoblásticos y granolepidoblásticos de cuarzo, calcita y opacos. Las gradaciones son fácilmente reconocibles y están caracterizadas por la presencia de niveles de minerales opacos o de granos de cuarzo. Algunas muestras presentan gran cantidad de opacos, mientras que otras suelen presentar niveles milimétricos de agregados finos de calcita. Se observaron en algunas metapelitas biotitas primarias cloritizadas y en kinks. En las zonas donde la deformación es mayor es común encontrar las metapelitas con textura lepidoblástica crenulada, en las que se reconoce una esquistosidad de pliegue y un clivaje de fractura, bandas conjugadas de crenulación $\left(S_{n}\right)$ sobre una $S_{n-1}$ de transposición. En algunos casos la esquistosidad de crenulación (strain -slip-cleavage) $-\mathrm{S}_{\mathrm{n}+1 \text { se }}$ superpone a una superficie anterior, $\mathrm{S}_{\mathrm{n}}$. La $\mathrm{S}_{\mathrm{n}+1}$ es considerada como una fase de deformación dúctil o semidúctil y estarían representando pequeñas fajas de cizallamiento.

Se han reconocido trazas fósiles (Aceñolaza et al. 1998) en buen estado de conservación en paquetes poco o nada deformados de metapelitas calcáreas de colores castaños. Estos niveles se presentan en carnadas tabulares presentando estratificación lenticular y gradada, laminación ondulítica y plano paralela. En el caso de las carnadas con estratificación, los lentes son de psamitas muy finas de hasta 30 centímetros. Los niveles con gradación no han podido ser utilizados como indicadores de polaridad de capa, dado que estas estructuras han sido reconocidas en bloques sueltos. La laminación plano paralela es milimétrica a centimétrica. El color de las láminas varía en función de la composición mineralógica desde negros a gris obscuro y desde castaños a gris verdoso.

Litofacies de metapsamitas finas Una gran variedad de estructuras sedimentarias se han reconocido en esta litofacies, tales como laminación plano paralela, gradación, ondulitas y microondulitas (ondulas simétricas con $\lambda=30 \mathrm{~cm}$, con $\mathrm{h}=10 \mathrm{~cm}$; ondulas asimétricas $\lambda=5-10$ $\mathrm{cm}$, con $\mathrm{h}=2-3 \mathrm{~cm})$, calcos de carga, estratificación cruzada de tipo hummocky. Los bancos suelen ser tabulares y lenticulares de espesor variable con coloraciones grises, castañas y violáceas. Los niveles más importantes se encuentran aflorando al noreste de la estancia la Salvaje $\mathrm{y}$ al este de la ruta 60. La estratificación cruzada de tipo hummocky ha sido reconocida en varias escalas, desde centimétrica a métrica, desarrollada en diferentes granulometrías. Es común encontrar metagabros, diques de metadiabasa y metalimolitas intercalados. Muchos niveles métapsamíticos tienen intercalaciones de metalimolitas con lentes metapelíticos.

Las metapsamitas de grano fino presentan textura granonematoblástica con matriz pelítica donde los granos de cuarzo, escasas plagioclasas y opacos se encuentran flotando en la matriz con textura lepidoblástica y granolepidoblástica constituida por granos de cuarzo, plagioclasa, sericita y/o muscovita. Los accesorios suelen ser turmalina, epidoto, apatito y circón. Se han encontrado granos de cuarzo de tipo monocristalino, de hábito bipiramidal corto. En otros casos las metapsamitas presentan mayor cantidad de microclina, plagioclasa, plagioclasa antipertítica y escasos opacos. Algunas muestras presentan una foliación caracterizada por el desarrollo de clivaje de tipo anastomosado. Se ha observado también biotita crenulada, muscovita, sericita, clorita y epidoto.

Las metapsamitas de grano grueso (sabulfticas) con textura granoblástica presentan agregados granulares de cuarzo y microclina, mientras que la biotita y el epidoto aparecen en los planos de foliación metamórfica. Algunas metagrauvacas presentan textura granular y están constituidas por cuarzo, feldespato potásico, anfíboles cloritizados, hornblenda, actinolita, actinolita/hornblenda, sericita, opacos, fragmentos líticos volcánicos y escasa biotita. En algunas muestras se observó la presencia de venas con abundante esfena y la paragénesis es explicada como producto de alteración hidrotermal, aunque en determinados casos se puede también pensar en un aumento en el grado metamórfico.

Algunas metapsamitas laminadas de grano fino, con textura granoblástica, presentan intraclastos psamíticos y pelíticos. Mineralógicamente están constituidas por cuarzo, sericita, plagioclasa, epidoto y clorita. Algunos niveles presentan importantes cristales de biotita. Los niveles de psamitas conglomerádicas ocurren esporádicamente como paquetes tabulares poco potentes, no superando el metro. Estos presentan clastos de cuarzo redondeado y subredondeado de hasta $5 \mathrm{~cm}$. Petrográficamente están constituidas por granos de cuarzo subangulosos a subredondeados y más escasamente de feldespatos. La matriz esta formada por granos de cuarzo, sericita, epidoto, opacos y plagioclasa.

Las metapsamitas afectadas por la intrusión de granitos que generaron metamorfismo de contacto presentan textura granoblástica en mosaico a poligonal granoblástica. Mineralógicamente están constituidas por microblastos xenomorfos de cuarzo, feldespato, biotita, presentando como accesorios circón y pirita.

Se han reconocido una serie de niveles de areniscas conglomerádicas, areniscas medias y finas constituidas por granos de cuarzo con textura en mosaico, cuarzo de alta temperatura, plagioclasa, microclina, biotitas crenuladas, fragmentos líticos de vulcanitas acidas -con texturas esferulíticas- y de metabasaltos con textura microlítica, sericita, clorita y opacos. Estos niveles indican un importante aporte volcánico $(5-10 \%)$ dentro de las sedimentitas.

Litofacies de metaarcosas Esta unidad se destaca en el paisaje y conforma cerros alargados en dirección noreste. Mineralógicamente están caracterizadas por una relación similar de porcentaje de cuarzo y feldespato, apareciendo como accesorios plagioclasa, líticos volcánicos, titanita, circón, opacos, turmalina y sericita en los planos de foliación. Las metaarcosas se encuentran en paquetes masivos y gradados. El feldespato potásico suele ser microclina y subordinadamente ortosa, aunque también aparece plagioclasa de tipo albita y bytownita. Algunos niveles de metaarcosas están caracterizados por presentar abundante óxido de hierro en la matriz, confiriéndole a la roca coloraciones ocres y borra de vino. Los constituyentes principales son cuarzo y microclina. En comparación con el resto de las unidades presenta escasa sericita.

Litofacies de metacuarcitas Chiron (1982) definió como Formación Salus a un conjunto de cuarcitas puras que afloran en las proximidades del parque homónimo. Esta unidad está representada por cuarcitas puras, presentando jocalmente importantes pátinas de óxidos de hierro, los afloramientos resaltan en el paisaje. Niveles de cuarcitas puras, similares, afloran como niveles de hasta 2 metros al sur de la Ciudad de Minas. Tal como lo sugirió Midot (1984) ocurren intercalaciones de hasta $2 \mathrm{~m}$ de espesor aproximado de niveles de brechas intraformacionales. Están constituidas casi exclusivamente por cuarzo aunque localmente presentan micas y pátinas de óxidos de hierro y de 
pequeñas intercalaciones de niveles políticos. Algunas cuarcitas presentan como accesorios cristales de calcita, cuarzo, epidoto, sericita, turmalina y opacos.

Litofacies de metacuarcitas con fucsita Esta ocurre de forma escasa y en lentes que no superan los dos metros de potencia. Estas cuarcitas se encuentran constituidas fundamentalmente por cuarzo subredondeado de fracción arena media presentando clastos dispersos de cuarzo de hasta $3 \mathrm{~cm}$, sericita, muscovita y fucsita; como accesorios presentan opacos y circón. Tienen variaciones en el contenido de fucsita: a medida que esta disminuye aumenta la proporción de muscovita. Esta unidad se encuentra aflorando al sudeste de la ciudad de Minas y al norte del cerro de Luis Meló, en contacto con calcáreos grises hacia el este y con esquistos biotíticos hacia el oeste. Esta última localidad forma parte de la Formación Zanja del Tigre. Cuarcitas con fucsita han sido señaladas por Spoturno et al. (1986) en la región de La Calera, localizada a pocos kilómetros al norte de la ciudad de Minas. Las muscovitas con cromo (fucsita) aparecen comúnmente en zonas donde existe reemplazo de carbonates asociados a depósitos de cuarzo - sulfuras.

FACIES CALCOCLÁSTICA Estas unidades podrían corresponder a espesas secuencias carbonáticas depositadas en aguas rasas. Aunque es difícil establecer un modelo de facies, se propone separar tentativamente las siguientes litofacies:

Litofacies de metacalcopelitas y metacalcopsamitas finas Conforman una unidad litológica bastante común y están caracterizadas por constituir importantes paquetes. Presentan comúnmente un acamamiento paralelo, regular, continuo, laminaciones milimétricas a centimétricas. Presentan intercalaciones milimétricas de pelitas, como así también intercalaciones de importantes paquetes de metabasaltos, metariolitas y metahialoclastitas. Constituye una de las unidades más ampliamente distribuida, además de presentar potentes paquetes, tal como puede observarse en el corte de la ruta panorámica 81. Presentan coloraciones gris claras y obscuras y castañas. Presentan muchas veces laminación plano paralela, estratificación cruzada de tipo hummocky, estratificación cruzada de bajo ángulo, laminación ondulítica y microondulítica, así como también niveles milimétricos constituidos principalmente por pirita. La presencia de estratificación erosiva en la cantera de piedralaja localizada en la ruta panorámica 81 , permitió reconocer, localmente, el tope y base de la sucesión sedimentaria que constituye la sinforma anticlinal de la ruta 81 y la antiforma sinclinal de La Oriental Dentro de las calcopelitas aparecen importantes bancos de metapelitas sericítícas intercaladas. Petrográficamente las calcopelitas están caracterizadas por presentar proporciones iguales de carbonato y cuarzo y sericita en fracción pelítica. Algunos niveles están constituidos por niveles milimétricos de carbonato con intercalaciones pelíticas.

Litofacies de metacalcoarenitas con intercalaciones de metapelitas Esta aflora escasamente y se encuentra representada por areniscas calcáreas finas a muy finas, de escasa potencia, con intercalaciones de pelitas y calcolimolitas. Las calcoarenitas presentan una coloración castaño-amarillenta. Los contactos con las unidades supra e infrayacentes suele ser neto. Presentan comúnmente coloraciones castañas. Los paquetes son de geometría tabular maciza, aunque se han reconocido estructuras sedimentarias tales como estratificación planoparalela y relictos de estratificación entrecruzada, estratificación plano paralela, a veces estratificación ondulítica, lenticular y estratificación cruzada generada por la migración de ondas (coarse grained ripples), ondulas simétricas. En general la laminación interna suele ser plano paralela. Es común que las metacalcoarenitas graden a metacalcolimolitas o metacalcopelitas. La potencia de las calcoarenitas es de pocos metros, mientras que las litologías a las que grada llegan a conformar decenas de metros. Petrográficamente, las metacalcoarenitas presentan textura granoblástica heterogranular con cuarzos subredondeados y subangulosos con textura cataclástica, feldespato potásico, flotando en una matriz carbonática con micas, wollastonita(?), turmalina y opacos. En la mayoría de los casos se reconoce una foliación penetrativa (slaty cleavage) donde la superficie de estratificación So es paralela a la $\mathrm{Si}$. Las estructuras encontradas podrían estar indicando un ambiente de playa frontal (shoreface) en un medio de transición, dado por la presencia de material arenoso gradando a material de granulometría limo - arcilla, de plataforma.

FACIES CONGLOMERÁDICA Metaconglomerados Esta unidad aflora escasamente en la comarca estudiada y se encuentra representada por paquetes poco potentes que pueden ser divididos en función de la composición de los mismos. Uno de los niveles de brechas conglomerádicas, aflora en contacto tectónico con la Formación Las Ventanas próximo a las canteras Burgeño. Presenta clastos estirados de granitos, gneisses, cuarzo y feldespato (Fig. 8a) de hasta $12 \mathrm{~cm}$, y una foliación muy marcada (norte-sur). El otro nivel es parte de una sinforma con plano axial N10 $0^{\circ}$ subvertical y se encuentra aflorando próximo a la estancia La Salvaje. Está constituido por clastos de cuarcitas, gneisses, anfibolitas, gabros, metapelitas, milonitas y de vulcanitas básicas e intermedias (Fig. 8b) de hasta 28 centímetros soportados por una matriz gravillosa. Los clastos se encuentran orientados según la dirección de foliación regional. Este conglomerado pasa gradualmente a niveles arcósicos, areniscas y finalmente a pelitas. Este conjunto litológico se encuentra hacia el este, intruido por una granodiorita (facies granodiorítico del Granito Minas). Hacia el este, ocurre una alternancia de bancos de grauvacas, pelitas y calcáreos. Al sur del arroyo del Canelón, en la charnela de la sinforma de la ruta 81 ocurre un nivel de conglomerado de poco espesor aparente $(3 \mathrm{~m})$ constituido por clastos de cuarzo fundamentalmente flotando en una matriz pelítico - arenosa. La foliación generó una re-orientación de los clastos. Este nivel de conglomerados se encuentra en contacto con un metagabro, al este y por metapelitas al oeste. Otros niveles de metaconglomerados aparecen intercalados con los niveles dolomíticos de mina Valencia. Estos, a diferencia de aquellos ubicados próximos a la estancia $\mathrm{La}$ Salvaje presentan una granoclasificación. Los clastos son de metapelitas, metapsamitas, metacuarcitas, dolomitas, volcánicas básicas y acidas. Un importante nivel de conglomerados constituido por clastos redondeados de cuarcita y en menor proporción de granitos deformados cementados por baritina se encuentra localizado al este de la ciudad de Minas y forman parte de un anticlinal buzante. El tamaño mayor de los clastos de cuarcita es de $20 \mathrm{~cm}$. La matriz está constituida por granos de cuarcita, granito y abundante sericita, posible fucsita, baritina, malaquita, pirita y calcopirita. Las texturas sedimentarias indican que la baritina es de tipo sin - depositacional. El origen de esta mineralización puede deberse a una importante adsorción de boro y bario de las aguas marinas.

\section{Ambiente de depositación del miembro sedimentario}

No existen para la región modelos de evolución de facies o sistemas depositacionales. Las rocas calcáreas del Grupo Lavalleja constituirían un buen ejemplo de plataforma carbonática proterozoica, siendo las rampas la forma más común, sobre relieves heredados de plataformas silicoclásticas (Grotzinger 1989). Esta unidad presenta una deformación importante, aunque desde el punto de vista paleoambiental puede considerarse como depositada en una plataforma carbonática afectada por la acción de olas y corrientes producidas durante episodios de tempestades en momentos de alternancia entre estabilidad e inestabilidad tectónica. Dada las asociaciones de las diferentes litofacies calcáreas y calcoclásticas, estructuras estromatolíticas y calcáreos, con laminaciones finas, más la abundancia de calizas dolomíticas, se puede suponer, siguiendo el esquema de Wilson (1975) que corresponde a un ambiente de plataforma restringida. Existen facies predominantemente pelíticas y otras predominantemente psamíticas. La depositación de las mismas pudo haber ocurrido mediante corrientes de turbidez en zonas de abanicos submarinos. Niveles menos potentes corresponden a facies conglomerádicas. Estas litologías se encuentran en contacto tectónico con mármoles. La presencia de fragmentos líticos volcánicos inmaduros en las psamitas y conglomerados sugiere flujos de detritos (debrisflow) y depósitos de canales fluviales desarrollados próximos a un arco. A partir del reconocimiento por lo menos cinco niveles de conglomerados, diferentes entre, sí se puede sugerir, que cada uno de ellos esté representando un ciclo sedimentario diferente. Aunque es dificil separar fehacientemente los distintos ciclos, puede reconocerse que en las series detríticas, el carácter transgresivo está dado por una disminución en el tamaño de grano, hasta niveles de grano muy fino. En algunos de los casos gradan a rocas carbonáticas, sugiriendo un pasaje de ambiente nerítico a litoral (sensu Visher 1965). Por otra parte, no fue posible reconocer límites de secuencias, ya sea por la mala calidad de los afloramientos o por la deformación que presenta todo el conjunto, que resultan de suma importancia para la interpretación de las facies y para el establecimiento de correlaciones estratigráficas precisas. Importantes mineralizaciones en baritina junto con pirita, calcopirita, esfalerita, galena, tetraedrita - tenantita y cuarzo, con pequeñas cantidades de oro y plata han sido descriptas para los depósitos de tipo Kuroko (Japón). La mención de estos minerales para la comarca en estudio sería compatible con mineralizaciones de sulfuros diseminados tanto distales como proximales vinculadas a centros volcánicos en una cuenca de trasarco. 

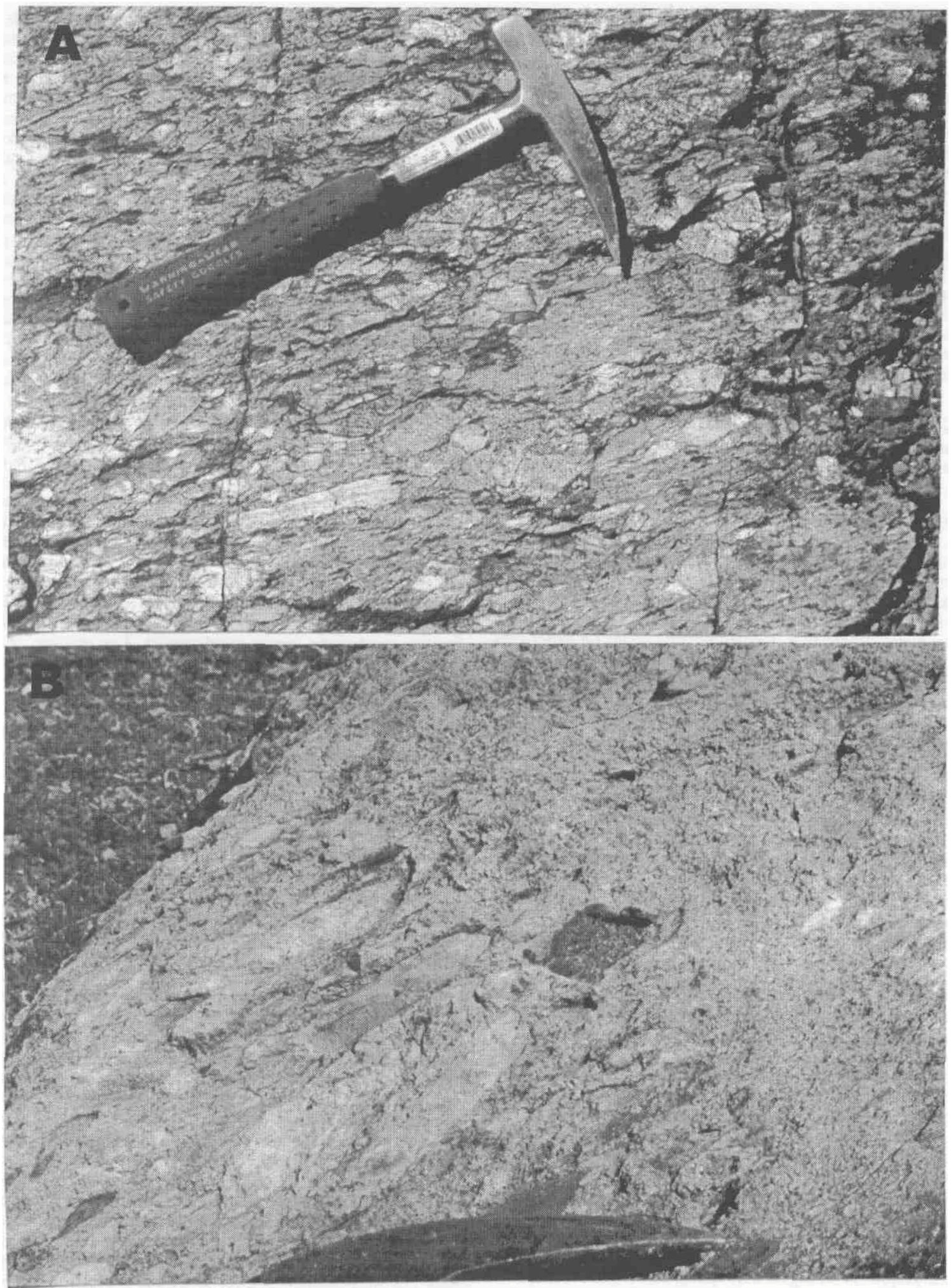

Figura 8 - (A) Metaconglomerado foliado, localizado próximo a la localidad de Nueva Carrara. (B) Metaconglomerado de la Formación Fuente del Puma, constituido por fragmentos de rocas volcánicas, cuarcitas, gabros y metapelitas.

\section{Ambiente de depositación del miembro sedimentario}

No existen para la región modelos de evolución de facies o sistemas depositacionales. Las rocas calcáreas del Grupo Lavalleja constituirían un buen ejemplo de plataforma carbonática proterozoica, siendo las rampas la forma más común, sobre relieves heredados de plataformas silicoclásticas (Grotzinger 1989). Esta unidad presenta una deformación importante, aunque desde el punto de vista paleoambiental puede considerarse como depositada en una plataforma carbonática afectada por la acción de olas y corrientes producidas durante episodios de tempestades en momentos de alternancia entre estabilidad e inestabilidad tectónica. Dada las asociaciones de las diferentes litofacies calcáreas y calcoclásticas, estructuras estromatolíticas y calcáreos con laminaciones finas, más la abundancia de calizas dolomíticas, se puede suponer, siguiendo el esquema de Wilson (1975) que corresponde a un ambiente de plataforma restringida. Existen facies predominantemente pelíticas y otras predominantemente psamíticas. La deposi- 
tación de las mismas pudo haber ocurrido mediante corrientes de turbidez en zonas de abanicos submarinos. Niveles menos potentes corresponden a facies conglomerádicas. Estas litologías se encuentran en contacto tectónico con mármoles. La presencia de fragmentos líticos volcánicos inmaduros en las psamitas y conglomerados sugiere flujos de detritos (debris flow) y depósitos de canales fluviales desarrollados próximos a un arco. A partir del reconocimiento por lo menos cinco niveles de conglomerados, diferentes entre, sí se puede sugerir, que cada uno de ellos esté representando un ciclo sedimentario diferente. Aunque es difícil separar fehacientemente los distintos ciclos, puede reconocerse que en las series detríticas, el carácter transgresivo está dado por una disminución en el tamaño de grano, hasta niveles de grano muy fino. En algunos de los casos gradan a rocas carbonáticas, sugiriendo un pasaje de ambiente nerítico a litoral (sensu Visher 1965). Por otra parte, no fue posible reconocer límites de secuencias, ya sea por la mala calidad de los afloramientos o por la deformación que presenta todo el conjunto, que resultan de suma importancia para la interpretación de las facies y para el establecimiento de correlaciones estrati gráficas precisas. Importantes mineralizaciones en baritina junto con pirita, calcopirita, esfalerita, galena, tetraedrita - tenantita y cuarzo, con pequeñas cantidades de oro y plata han sido descriptas para .los depósitos de tipo Kuroko (Japón). La mención de estos minerales para la comarca en estudio sería compatible con mineralizaciones de sulfuros diseminados tanto distales como proximales vinculadas a centros volcánicos en una cuenca de trasarco.

MIEMBRO VOLCÁNICO En esta unidad están representadas rocas volcánicas y volcaniclásticas de composición tanto básica como acida, existiendo de forma subordinada términos de composiciones intermedias. Estas rocas se encuentran intercaladas dentro del miembro sedimentario. Los diferentes términos litológicos de composición básica están representados por metabasaltos amigdaloides, vesiculares y macizos, metabasandesitas, metandesitas, metadiabasas, metabrechas basálticas y andesíticas; mientras que los términos ácidos por metariolitas, metadacitas, metahialoclastitas y metabrechas. Se han reconocido posibles estructuras de lavas almohadilladas (Fig. 9), interdigitadas con secuencias metasedimentarias tales como metacalcopelitas y metaarcosas, en las que se han reconocido contactos intrusivos. Los contactos son netos y concordantes en su gran mayoría.

Metabasaltos Los metabasaltos afloran como cuerpos elongados con dirección noreste y constituyen las volcanitas más abundantes. El afloramiento mejor desarrollado es aquel que constituye el núcleo de la sinforma de la ruta 81 . A nivel mesoscópico se separaron en metabasaltos macizos y vesiculares. Esta litología suele presentar foliación metamórfica muy marcada en los bordes de los cuerpos haciéndose menos notoria hacia su centro. Esto ha sido utilizado en muchos casos para estimar no sólo su potencia si no para separarlo de cuerpos adyacentes. La caja suelen ser metapelitas o metacalcopelitas como así también metariolitas. Se han observado numerosos contactos con bordes calcinados. Muchas muestras presentan una textura volcánica característica indicando un origen netamente extrusivo dada por la presencia de rasgos heredados como la suborientación de los minerales de la pasta.

Petrográficamente presentan textura porfírica a microporfíricas presentando fenocristales de plagioclasa $\left(\mathrm{An}_{14}\right)$ en una pasta intersertal constituida por plagioclasa acida, hornblenda, abundante epidoto, opacos y pirita. En otros casos presentan relictos de textura microlítica subfluidal o texturas subofíticas o microlíticas porfiricas o microlíticas vesiculares con plagioclasa poikilítica albitizada en una matriz constituida fundamentalmente por clorita y epidoto. Algunas plagioclasas presentan antipertitas. Son comunes las inclusiones de esfena y opacos. Las amígdalas se encuentran parcialmente rellenas por calcita o totalmente substituidas por epidoto. Estas son de formas redondeadas de hasta $5 \mathrm{~mm}$ de diámetro. En algunas muestras fueron reconocidas texturas esferulíticas y variolítica.. Petrográficamente se reconoce una espilitización importante, tal como fuera ya reconocida por Midot (1984). Dada las texturas que presentan los metabasaltos y la asociación con metacalizas y metapelitas, podrían estar constituyendo flujos lávicos basálticos. En algunos casos, fueron reconocidas, a nivel de campo, estructuras en lavas almohadilladas.

Las metadiabasas presentan textura dolerítica y están constituidas por plagioclasa, piroxenos (?) epidotizados, epidoto, calcita, y cuarzo. Las metandesitas basálticas albíticas presentan textura intergranular. Están constituidas mineralógicamente por plagioclasa de composición albita, biotita y piroxenos (augita) cloritizados y opacos. Algunas metaandesitas presentan textura subofitica, con albita euhedral a subhedral encerrada parcialmente por cristales de máficos alterados a anfíbol (actinolita), cloritas y epidoto, reflejando, seguramente la alteración de piroxenos. Estas rocas corresponderían a los términos subvolcánicos del magmatismo básico, constituyendo filones y diques, probables conductos de alimentación.

Las metabrechas volcánicas andesíticas presentan cristales de plagioclasas albitizadas y saussuritizadas, cuarzo, piroxenos con macla simple epidotizados, y abundantes opacos como bordes de reabsorción de anfiboles, epidoto en una matriz constituida por microlitos de plagioclasa, opacos y calcita.

Metariolitas Esta litología ocurre comúnmente asociada a metabasaltos ya sean macizos o vesiculares. Normalmente son poco potentes no superando los 6 metros. Esta unidad se encuentra aflorando

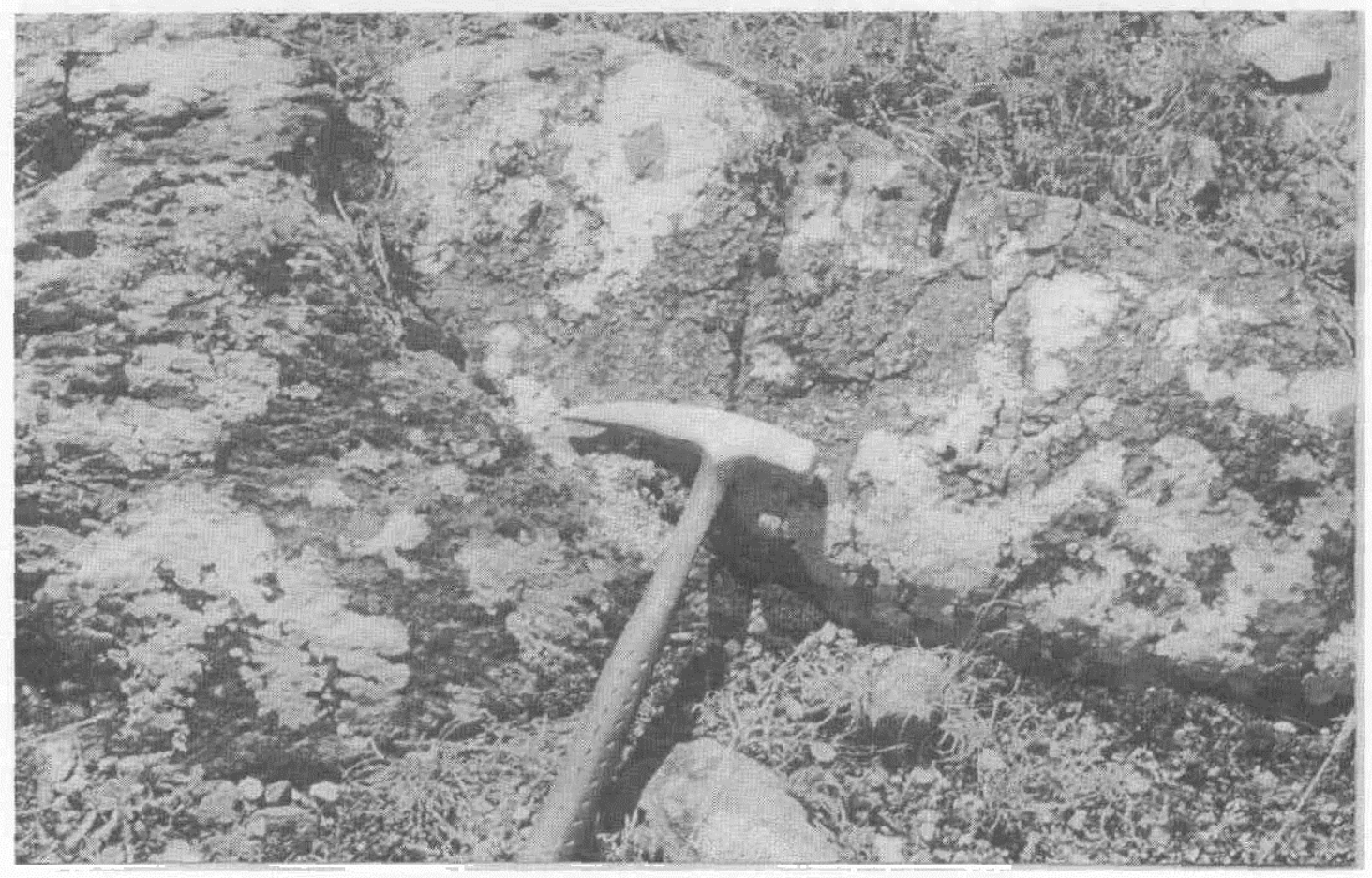

Figura 9 - Metabasaltos de la Formación Fuente del Puma presentando estrucura en almohadilla 
en forma de diques o flujos lávicos de composición riolítica o incluso como volcaniclásticas (flujos ignimbríticos y metahialoclastitas) Interestratificadas con la sucesión metasedimentaria y con metabasaltos (Sánchez Bettucci et al. 1997). En el ámbito de afloramiento los diques son discordantes, con contactos netos, presentan una foliación poco marcada que se evidencia en el estudio petrográfico por alineación de minerales. Presentan colores claros, blanquecinos a castaños. Petrográficamente presentan textura porfírica determinada por fenocristales de oligoclasa, feldespato potásico y cuarzo. La pasta suele ser, según el caso, granofírica, microgranosa o felsítica, constituida por feldespato, cuarzo, escasa biotita y/o muscovita. Los accesorios más comunes son apatita y opacos.

Las met alavas son concordantes con la sucesión volcanosedimentaria, en la cual están interestratificadas. Algunas metariolitas presentan textura granoblástica con matriz holocristalina y están constituidas por ortosa, plagioclasa, mirmequita, cuarzo euhedral, calcita, epidoto, clorita, escasa muscovita y opacos (Fig. 10). Así mismo se han reconocido metariolitas con texturas esferulíticas, constituidas por ortosa, plagioclasa, cuarzo y accesoriamente clorita, biotita cloritizada. Los efectos del metamorfismo están marcados por una importante albitización, cloritización y epidotización de la mineralogía original.

Metahialoclastitas y metabrechas Las metabrechas de composición básica presentan una tendencia monogénica. El tamaño de los clastos varía entre 1 y $18 \mathrm{~cm}$. Los distintos niveles presentan una orientación concordante con la deformación y foliación metamórfica. Se encuentran intercaladas con la secuencia metasedimentaria. Estas unidades afloran al oeste de la estancia El Castillo de Batlle. Las brechas del Castillo fueron definidas por Midot (1984) como productos piroclásticos, sin granoclasificación, presentando escaso cemento, representado por sericita y clorita. La composición de éstas rocas suele ser variada, la mayoría son de composición riolítica y presentan una laminación primaria bien preservada, subordinadamente ocurren metahialoclastitas de composición dacítica. Muchas de las metahialoclastitas se encuentran parcial o totalmente albitizadas y están caracterizadas petrográficamente por presentar texturas porfíricas. Mineralógicamente presentan fenocristales suborientados de plagioclasa, feldespato potásico y cuarzo sobre una pasta de textura felsítica fluidal. Algunas muestras presentan texturas esferulíticas, cuarzos engolfados y cristales de plagioclasa corroídos. Las metabrechas acidas pueden ser riolíticas o dacíticas. Estas últimas se encuentran caracterizadas petrográficamente por fenocristales de plagioclasa, cuarzos engolfados y feldespato potásico corroído y opacos.
Miembro gabros hornbléndicos Metagabros Esta unidad aflora como cuerpos Ientiformes elongados en la dirección de la deformación $\left(\mathrm{N} 30^{\circ} \mathrm{E}\right)$ o irregulares al oeste de la Formación Las Ventanas, en contacto con metapelitas, al este del Abra de Coto y como un colgajo (roof pendant) dentro de microsienitas, al norte del cerro del Horno. La foliación es heterogénea a lo largo del cuerpo, haciéndose más importante hacia los bordes. Petrográficamente presentan textura granosa gruesa y fina y están compuestos por hornblenda, hornblenda poikilítica, plagioclasa albitizada, substitución isomórfica de olivina por opacos y de ilmenita por titanita. Accesoriamente se observan opacos, apatita, pirita y calcopirita. Algunas muestras presentan actinolita, clorita, sericita, epidoto y opacos como minerales de alteración producto de la desestabilización del anfibol. Se han reconocido texturas subofíticas relícticas, en las que el piroxeno ha sido totalmente reemplazado por hornblenda, indicando que algunos de estos cuerpos posiblemente corresponderían a intrusivos hipabisales. La asociación de minerales metamórficos esta dada por albita, hornblenda verde, epidoto y clorita, indicando una asociación mineralógica típica de facies esquistos verdes. En algunas muestras se observó la transición en la facies metamórfica de esquistos verdes superior a anfibolita inferior, dada por la recristalización de plagioclasa (oligoclasa) junto con hornblenda azul verdosa. Evidencias de metamorfismo retrógrado, caracterizado por la presencia de tremolita-actinolita, han sido reconocidas.

Formación Zanja del Tigre Esta formación se encuentra localizada este del corrimiento Pan de Azúcar (Machado \& Fragoso Cesar 1987) y del corrimiento La Oriental (Cosarinsky 1997), en la sierra de Carapé, en contacto tectónico con el Complejo homónimo y como lascas tectónicas dentro de éste. La estructura corresponde a una sucesión de antiformas y sinformas abiertas con ejes inclinando al sudoeste. Esta formación se encuentra representada litológicamente por cuarcitas muscovíticas, fucsíticas, esquistos biotíticos y muscovíticos, esquistos andalucíticos, metacalizas marmóreas, mármoles, metagabros y anfibolitas, con metamorfismo en facies esquistos verdes superior y anfibolita.

METAGABROS Esta unidad aflora en contacto con esquistos cordieríticos y muscovíticos, al este y con metadolomitas diopsídicas al oeste, próximo al frente del corrimiento Pan de Azúcar. Petrográficamente presentan textura granoblástica a granonematoblástica constituidos mineralógicamente por andesina, anfibol, piroxenos uralitizados, epidoto, opacos, titanita, calcita y cuarzo. Los anfíboles (acti-

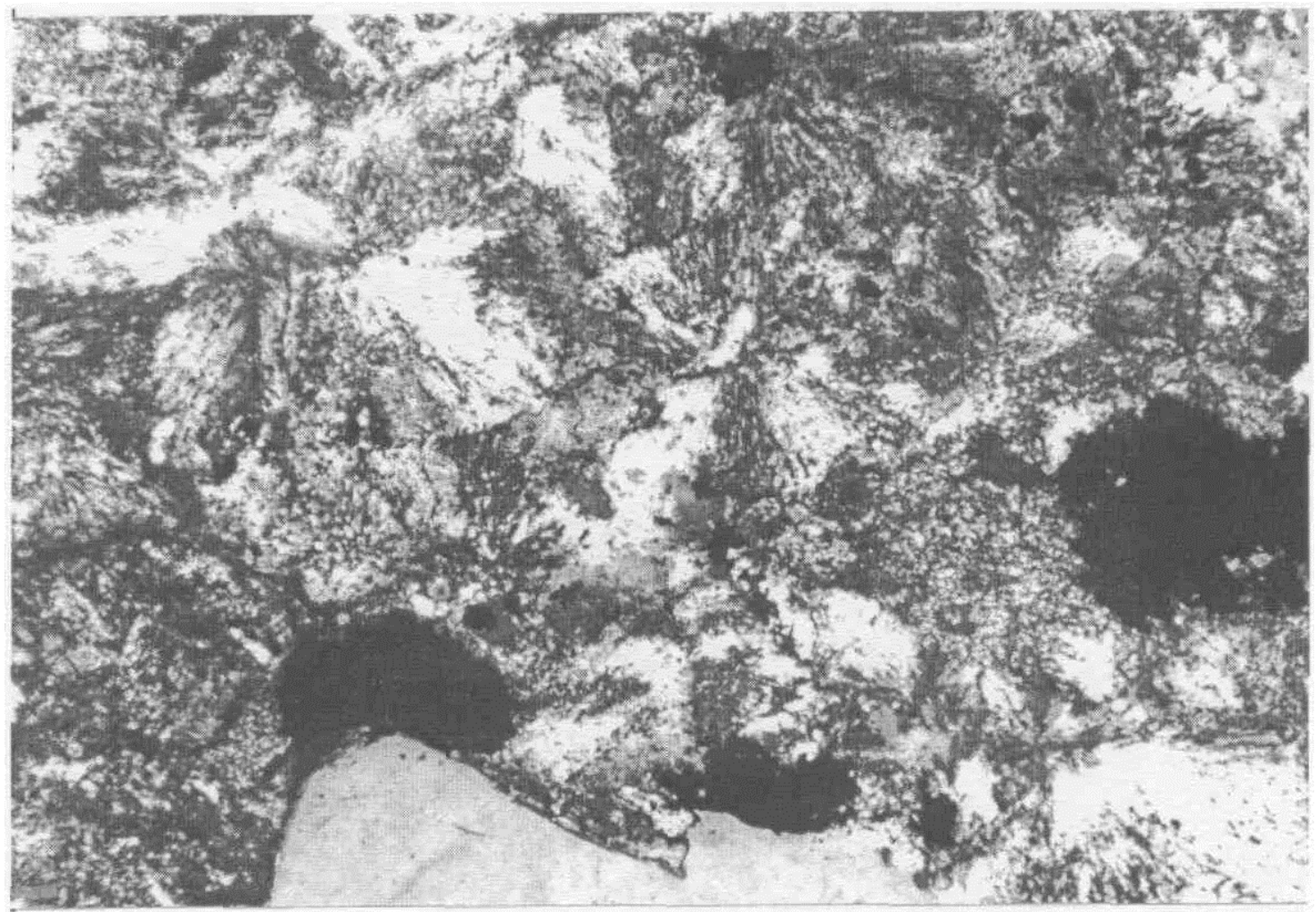

Figura 10 - Metariolita presentando texturas esferuliticas preservadas. 
nolita) constituyen cristales mayores pudiendo en algunos casos formar cúmulos rodeando a plagioclasas euhedrales. Generalmente las plagioclasas son anhedrales y suelen presentar maclas simples y polisinteticas. Los cristales de actinolita/hornblenda son poikiloblásticos presentando inclusiones de plagioclasa, apatito y opacos (pirita). Algunos cristales presentan cribado y bordes corroídos por la pasta. Las plagioclasas de composición andesina son anhedrales y suelen encontrarse bastante alteradas. La esfena es abundante y aparece en formas euhedrales y en bandas estiradas. En algunas muestras se reconocieron texturas porfíricas y cúmulo porfíricas con una pasta microgranosa relíctica. En otros casos la asociación mineralógica esta dada por anfíbol -hornblenda xenoblástíca a hipidioblástica-, oligoclasa, cuarzo, apatito y opacos indicando un metamorfismo en facies anfibolita. Las distintas asociaciones mineralógicas encontradas son:

andesina + actinolita + esfena + clorita + epidoto + calcita $(+$ clorita $)$

andesina + actinolita + esfena + clorita + granate + calcita

oligoclasa + hornblenda verde + cuarzo + apatito + opacos

ESOUISTOS MICÁCEOS Los esquistos micáceos presentan textura lepidoblástica y están constituidos fundamentalmente por biotita, escasa muscovita y cuarzo que en algunos casos se presentan como nodulos con textura granoblástica. Accesoriamente ocurre feldespato, epidoto, circón, clorita, sericita y opacos. Los minerales opacos en algunas muestras constituyen una accesorio importante. Se han reconocido en algunas muestras efectos de deformaciones rotacionales con sombras de presión asimétricas y una esquistosidad interna que fue rotada de su posición original. En otros casos es común encontrar esquistos con textura lepidoblástica con bandas granolepidoblásticas. El bandeado tectónico está caracterizado por una crenulación de la esquistosidad. Algunas muestras señalan texturas relícticas tales como plagioclasas con zonación, de la roca original (pilotaxíticas) aunque igualmente se observa una importante orientación de los granos minerales y generación de textura granolepidoblástica. Al igual que en la Formacion Fuente del Puma se han reconocido esquistos con fucsita. Estos paquetes se encuentran localizados al este de la sierra Cuchilla Grande, como intercalaciones tectónicas en el Granito la Calera. Suelen presentar una potencia aparente del orden de los cinco metros y una extensión longitudinal entre 20 y 35 metros. Petrográficamente presentan una textura lepidoblástica a granolepidoblástica. Están constituidos por granos de cuarzo, muscovita fucsita, circón, sericita, turmalina y opacos. Al igual que los esquistos fucsíticos anteriormente descriptos el porcentaje de muscovita aumenta a medida que disminuye la fucsita.

ESOUISTO CUARZO -FELDESPÁTICO CON MUSCOVITA Y/O BIOTITA Los esquistos derivados de metapsamitas cuarzosas presentan granos de cuarzo y feldespato granulados con extinción ondulosa dispersos en una matriz fina constituida por cuarzo, escaso feldespato, muscovita y/o biotita, homblenda, (actinolita) y opacos.

ESQUISTOS GRANA TÍFEROS Esta unidad se caracteriza por presentar textura metamórfica porfiroblástica y presentar blastos de granate en una matriz constituida por cuarzo, biotita, muscovita y accesoriamente opacos, sillimanita, circón y turmalina.

ESOUISTOS CLORÍTICOS Y CALCOESOUISTOS CLORÍTICOS Los esquistos semi-pelíticos arenosos con bandeado composicional suelen ser comunes, éstos presentan niveles más ricos que otros en biotita con relación al cuarzo o al resto de los componentes. Los esquistos cloríticos y los calcoesquistos cloríticos presentan coloraciones verdosas y muy buen desarrollo de esquistosidad. Esta litología aflora escasamente y se encuentra asociada a importantes fallamientos tal como el corrimiento La Oriental. Petrográficamente presenta textura lepidoblástica constituida fundamentalmente por clorita y de forma subordinada epidoto, biotita, calcita, cuarzo plagioclasa ehuedral (albita) y opacos. El porcentaje de clorita como constituyente principal generalmente es mayor al $85 \%$.

ESQUISTOS TREMOLÍTICOS Y/O ACTINOLÍTICOS Los esquistos tremolíticos se encuentran caracterizados petrográficamente por una textura nematoporfiroblástica. Mineralógicamente presentan tremolita, cuarzo, talco escasa clorita, calcita y opacos. La ocurrencia de tremolita representa una excelente isograda y coincide aproximadamente con el inicio de la facies anfibolita (Bucher \& Frey 1994). Por otra parte, la presencia de esquistos tremolíticos donde las plagioclasas se encuentran substituidas enteramente por calcita y la proximidad de esquistos cloríticos donde algunos de estos presentan lentes calcáreos, tal como fue descripto por Midot (1984) deja la sospecha de que se trate de fenómenos de metamorfismo hidrotermal. Los niveles tre- molíticos más importantes han sido reconocidos en las proximidades de la mina La Oriental, donde ocurren también esquistos cloríticos, esquistos talcosos, metacalizas dolomíticas e intercalaciones de hialoclastitas acidas subordinadas. Los esquistos actinolíticos presentan textura lepidoblástica y granonematoblástica y están constituidos mineralógicamente por fenoblastos de actinolita, plagioclasa, cuarzo, epidoto, calcita y clorita. Se sugiere, a partir de las relaciones de campo y características petrográficas un origen ígneo, más precisamente, gabros.

ESQUISTOS TALCOSOS Esta unidad aflora escasamente y se la ha encontrado al norte del arroyo Perdido en el camino a cerro Pelado en el departamento de Lavalleja. Presentan fábrica penetrativa con orientación planar y algunas veces bandeado composicional. Los esquistos talcosos se encuentran asociados a calcoesquistos anfibólicos, que también afloran escasamente. Estos últimos están constituidos por biotita, calcita y anfiboles (tremolita-actinolita), presentando subordinadamente clorita y opacos. Las ultimas tres unidades litológicas son interpretadas como producto de reacciones de metamorfismo retrógrado de rocas originalmente calcosilicáticas y metapelíticas, donde las reacciones más comunes son:

Para rocas calcosilicáticas

$\begin{array}{lll}\text { anortita } & \rightarrow & \begin{array}{l}\text { minerales del grupo del epidoto }( \pm \text { sericita }) \\ \text { carbonates } \\ \text { tremolita-actinolita }\end{array} \\ \text { tremolita } \rightarrow & \text { talco }\end{array}$

Para metapelitas

$\begin{array}{lll}\text { granate } & \rightarrow & \text { clorita } y / o \text { biotita } \\ \text { biotita } & \rightarrow & \text { clorita } \\ \text { ilmenita } & \rightarrow & \text { esfena }\end{array}$

ilmenita $\rightarrow \quad$ esfena

Además, existen evidencias de alteración potásica y sericitización, donde la alteración profilítica genera cloritización y alteración argilíca. Asimismo, la turmalinización encontrada en algunas muestras es un fenómeno común en las proximidades de intrusiones graníticas.

MÁRMOLES Y CALIZAS MARMÓREAS Los mármoles, rocas calcáreas con metamorfismo, donde los carbonates son dominantes, están constituidos casi exclusivamente por calcita y pequeñas cantidades de cuarzo y filosilicatos. Esta unidad se encuentra en contacto tectónico con rocas graníticas, granodioríticas a monzograníticas con escasas tonalitas asociadas y están afectadas por metamorfismo. Los mármoles puros (e.g. cantera de Piedrahita Hnos.) e impuros ocurren como cuerpos elongados o lenticulares de dimensiones variables, a veces asociados a una sucesión de esquistos micáceos, cuarcitas, areniscas, orto y para anfibolitas y paragneisses con dirección noreste. Generalmente se presentan con estructura maciza. Se han reconocido intercalaciones de metamargas constituidas por actinolita, biotita, cuarzo, calizas, dolomías y opacos.

CALIZAS DOLOMÍTICAS SILÍCEAS CON DIÓPSIDO Esta litología presenta textura granoblástica representada por cristaloblastos subredondeados cuarzo, calcita, diópsido, feldespato potásico, plagioclasa y epidoto sobre una matriz de grano fino con cuarzo, escaso feldespato potásico, plagioclasa, muscovita, diópsido, circón, clorita y esfena. El diópsido presenta un hábito prismático con maclado simple y representa el constituyente más importante $(50 \%)$. La asociación mineralógica indicaría un facies anfibolita superior.

ESOUISTOS CORDIERÍTICOS Constituyen delgados bancos localizados al oeste del corrimiento Puntas del Pan de Azúcar. Macroscópicamente corresponde a una roca de coloraciones verdosas y gris clara a blanquecina, presentando una fábrica direccional dada por la orientación de los minerales micáceos. Petrográficamente presenta textura lepidoblástica con desarrollo de esquistosidad de crenulación. La cordierita ocurre bajo la forma de porfiroblastos. Las evidencias petrográficas señalan que al momento de crecimiento de la cordierita la roca estuvo sometida a esfuerzos considerables. La asociación mineralógica está dada por muscovita, cuarzo, feldespato potásico, cordierita, sillimanita, biotita y turmalina y corresponde a la zona de sillimanita superior (Yardley 1988) de rocas pelíticas a altas temperaturas y presiones moderadas.

ANFIBOLITAS ORTO Y PARA DERIVADAS Las anfibolitas se encuentran aflorando al este de las unidades anteriormente descriptas y están en contacto ya sea con esquistos micáceos o granitos protomiloníticos. La forma general de los afloramientos es lenticular siguiendo la dirección de la foliación principal. Presentan una foliación caracterizada por la orientación de cristales de hornblenda de hasta 3 
mm. en cuyos bordes -en algunos casos- se observa una alteración a actinolita, la plagioclasa (albita y/o oligoclasa) es el segundo mineral en abundancia y puede aparecer parcialmente alterada a carbonato y clorita. La proporción de cuarzo es baja y presenta extinción ondulosa y textura en mortero. Aunque no se puede generalizar, la mayoría de los contactos son de tipo tectónico, encontrándose cabalgados por granitos protomiloníticos. Petrológicamente, se trata de rocas de grano medio a fino constituidas por cristales de hornblenda sobre una matriz feldespática. Petrográficamente fueron definidas por Preciozzi (1989d) como rocas con texturas granoblásticas a granonematoblásticas con homblenda, plagioclasas básicas, cuarzo y opacos. Fue posible separar petrográficamente a las anfibolitas en orto y para-derivadas. Se definen aquí como anfibolitas aquellas litologías orto y para-derivadas que han sido afectadas por un metamorfismo en facies anfibolita inferior y superior, y a aquellas que se encuentran en la transición entre facies esquistos verdes a anfibolita, y que no pertenecen al Complejo Carapé. Las primeras se caracterizan petrográficamente por una textura granonematoblástica y están compuestas por hornblenda verde y parda $(60 \%$ a $80 \%$ ), plagioclasa albitizada (5 a 20\%), cuarzo (O a 5\%), biotita parda, clorita y, accesoriamente, por circón, titanita, apatita y opacos. Las anfibolitas orto-derivadas presentan texturas granoblásticas y granolepidoblásticas y mineralógicamente están constituidas por hornblenda verde y parda, plagioclasa albitizada, andesina, epidoto, biotita parda, clorita, cuarzo y, accesoriamente circón, esfena, apatita y opacos. Algunas muestras presentan una textura porfiroide caracterizada por el intercrecimiento de grandes cristales de hornblenda, a veces poikiloblástica sobre una matriz fina. Se reconoce una textura relíctica subofitica dada por los anfiboles y plagioclasas. Se puede sugerir, dada las características petrográficas que el protolito de las mismas corresponda a un gabro. Las paraanfibolitas presentan una mineralogía similar, pero difieren en que presentan un porcentaje significativamente mayor de cuarzo y una abundante existencia de turmalina, apatita y circón subredondeados como accesorios. La textura está dada por un bandeado dado por niveles de plagioclasa y anfibol y niveles de cuarzo. Las relaciones de campo -aparecen intercaladas con esquistos micáceos y sin contactos netos-, la textura y la abundancia de los minerales accesorios permiten suponer un protolito sedimentario (psamitas de grano fino a medio). Algunas anfibolitas presentan una mineralogía propia de transformaciones retrógradas (plagioclasas saussuritizadas, hornblenda cloritizada) que, en coexistencia con actinolita + hornblenda + oligoclasa/albita, indicaría una transición de facies anfibolita a esquistos verdes -zona de biotita y clorita- (Yardley 1988). No se han observado anfibolitas piroxénicas con texturas ofíticas ó doleríticas descriptas por Preciozzi \& Pena (1990).

ESQUISTOS ANDALUCÍTICOS Este conjunto litológico se lo ha encontrado aflorando escasamente, en contacto con esquistos biotíticos. Constituye un banco de un metro de espesor aparente y de 15 metros de longitud. Se encuentra caracterizado por la presencia de andalucita en porfiroblastos de hasta $2 \mathrm{~cm}$, biotita, muscovita, cuarzo y óxidos de hierro. Esta asociación mineralógica correspondería a la zona de cordierita (Yardley 1988) dado que la andalucita puede ocurrir en esta zona en rocas relativamente ricas en $\mathrm{Fe}$ coexistiendo con biotita pero no con cordierita.

MIGMATITAS El conjunto de rocas definidas texturalmente corno migmatitas se encuentran aflorando al este de la ciudad de Pan de Azúcar. Estas rocas están caracterizadas por texturas estromáticas y moteadas, dada por la alternancia de niveles centimétricos de neosoma y mesosoma. Esta disposición sería el resultado de una extracción de líquido anatéctico o bien ser heredada de las metapelitas iniciales donde el leucosoma representaría niveles ricos en material granítico (Kornprobst 1996). Petrográficamente el leucosoma está constituido por cuarzo y feldespato, mientras que el melanosoma por anfibol, biotita, cuarzo y feldespato.

GEOQUÍMICA Los primeros análisis químicos del volcanismo del Grupo Lavalleja fueron realizados por Midot (1984). Este autor separó, por un lado cuatro grupos de litologías básicas: diabasas albíticas, volcanitas microlíticas vesiculares, vulcanitas microlíticas macizas, y por otro las rocas acidas. Posteriormente, Gómez Rifas (1995) presentó seis análisis químicos de rocas basálticas localizada en la cañada del Espinillo, próxima a mina Valencia. A partir de los resultados de estos análisis, este autor sugirió que los metabasaltos evolucionan a traquiandesitas sufriendo concomitantemente espilitización y por otra parte separó una serie más evolucionada vinculada a las fases finales de la evolución del Grupo Lavalleja. Se sugiere, a partir del relevamiento de campo y del estudio petrográfico realizado sobre las rocas aflorantes en la cañada del Espinillo que las litologías analizadas por Gómez Rifas (1995) corresponden a metagabros que se encuentran intruyendo a rocas metapelíticas en vez de rocas metabasálticas. Sánchez Bettucci (1998) realizó análisis químicos a 15 muestras de rocas ígneas pertenecientes al Grupo Lavalleja, de éstas, siete corresponden a anfibolitas, siete a metagabros y una a un metabasalto. Los porcentajes de $\mathrm{SiO}_{2}$ varían entre un $49 \%$ a un $51 \%$ para las anfibolitas y metabasaltos, mientras que los valores más bajos corresponden a los metagabros ( 44 a $48 \%$ de $\mathrm{SiO}_{2}$ ).

Sánchez Betucci (1998) sugirió que las muestras analizadas pertenecientes al Grupo Lavalleja presentan contenidos en Ni separables en dos grupos: el primero con valores entre 164 a 56 y el segundo entre $41 \mathrm{y} 3 \mathrm{ppm}$. Este último grupo podría estar indicando un manto evolucionado y una importante diferenciación, mientras que el primer grupo muestra que corresponden a metabasaltos poco evolucionados. Asimismo, Sánchez Betucci (1998) sugirió a partir del diagrama de tierras raras normalizadas a condrito (Sun 1982), tres grupos de rocas que responden a un comportamiento similar, pero que difieren en los contenidos relativos de dichos elementos. El primer grupo, integrado por metagabros, menos definido, presenta un marcado enriquecimiento en tierras raras livianas a diferencia de las pesadas, donde la curva tiene un patrón relativamente empinado; el segundo grupo, representado por anfibolitas y metabasaltos subordinados, presenta un menor enriquecimiento en elementos livianos con respecto al grupo anterior, presentando un diseño menos empinado que el primer grupo; y por último, el tercer grupo representado por metagabros presenta una curva casi horizontal, mostrando un contenido más o menos constante en todas las tierras raras. El patrón de este último grupo es similar al de una roca tipo MORB, pero con un marcado enriquecimiento general en todos los elementos (Fig. 11). Es decir que podría tratarse de una roca oceánica originada a partir de un menor grado de fusión parcial del manto que el MORB. En este contexto, las rocas comprendidas en los otros grupos podrían representar rocas oceánicas de carácter más alcalino, reflejado por el enriquecimiento en elementos livianos, siendo el primero más alcalino que el segundo. Al estar el carácter de alcalinidad inversamente relacionado al grado de fusión parcial, se podría suponer que los tres grupos de rocas están genéticamente relacionados según una evolución magmática tendiente a un aumento en el grado de fusión. Por otra parte, pudo reconocerse no solo petrográficamente sino también a partir de diferencias en el comportamiento geoquímico que los basaltos del Grupo Lavalleja son de tipo oceánico presentando variaciones composicionales. Estas variaciones pueden deberse no sólo a la baja presión de fraccionamiento de rocas subvolcánicas en la(s) cámara(s) magmática(s), si no también al fraccionamiento sólido - líquido que acompaña la fusión del manto. Asimismo, la cantidad importante de vesículas presentes en los metabasaltos indica la presencia de altos contenidos en volátiles en el magma. Saunders \& Tarney $(1979,1991)$ y Dick (1982) sugirieron que esta última característica constituye la diferencia entre los basaltos tipo MORB y aquellos de las cuencas de trasarco. Por otra parte, Sánchez Betucci (1998) sugirió que la presencia de clinopiroxeno en algunas de las muestras es atribuible (sensu Saunders \& Tarney 1991) al alto fraccionamiento de los magmas de las cuencas de trasarco. Asimismo, estos autores consideran que las composiciones de los basaltos e cuencas de trasarco resultan similares a los MORB y que

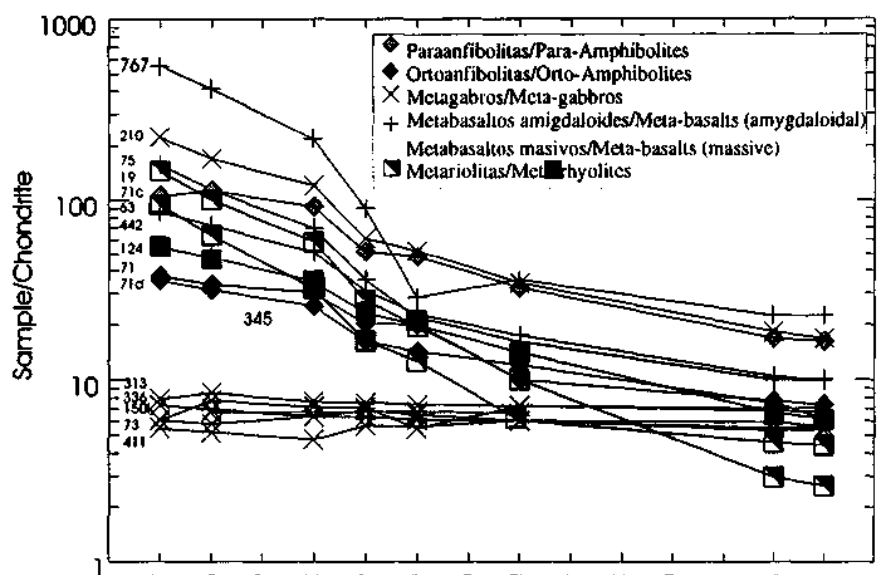

La Ce PT No Sm Eu Gd Tb Dy Ho Er im Vo Lu Figura 11 - Diagrama de normalización de REEa Condrila (Sun 1982) para las rocas del grupo Lavalleja (Sánchez Bettucci 1988). 
frecuentemente, pero no siempre muestran una delicada diferencia con éste, siendo en general transicional entre un MORB y los basaltos de arco islándico debido a que la fuente de los basaltos de trasarco se encuentran contaminados o metasomatizados por los fluidos de la zona de subducción. Las evidencias a favor de la existencia de una fuente de BAB son: empobrecimiento, en algunos casos en HFS, especialmente en $\mathrm{Nb}$ y Ta; tendencias altas en $\mathrm{K}, \mathrm{Rb}, \mathrm{Ba}$ y $\mathrm{Sr}$ en algunas muestras con respecto al MORB; el patrón prácticamente plano en REE a escasamente enriquecido con respecto al MORB, la poca abundancia de las tierras raras indica una fuente empobrecida; el La es variable pero el enriquecimiento en muchos magmas tipo MORB es común; se encuentran empobrecidos en relación al MORB en $\mathrm{Cr}$, Ni y Co. Como es sabido los BAB y los N-MORB presentan signaturas bastante similares, además los primeros suelen presentar bajas relaciones $\mathrm{Ti} / \mathrm{Zr}$, altas relaciones $\mathrm{Ti} / \mathrm{V}(>50)$, altas relaciones $\mathrm{Ti} / \mathrm{Se}(>250)$, enriquecimiento en L-REE $(\mathrm{Ce} / \mathrm{Yb}>3)$. Es probable que en la génesis de estos magmas habría estado involucrada la litosfera sub-continental, dada la evolución desde magmas basálticos hasta riolíticos, incluyendo material volcaniclástico o bien que se hallan generado durante la etapa incial de apertura de la cuenca de trasarco (Sánchez Betucci 1998).

DISCUSIÓN Las asociaciones petrotectónicas del cinturón Dom Feliciano en esta porción del Uruguay esta representada por. una asociación volcánica básica, acida e intermedias subordinadas, gabros tholeíticos y anfibolitas genéticamente relacionadas. La suite volcánica presenta cantidades variables de intercalaciones volcaniclásticas, esta representa un magmatismo alcalino a subalcalino. La importante cantidad de vesículas en los metabasaltos sugiere un emplazamiento subácuea somero. La cantidad de rocas volcánicas acidas es menor en relación a las básicas, presentan evidencias de enfriamiento rápido, dada por las texturas de desvitirificación. El grado metamórfico que caracteriza a estas litologías es un facies de esquistos verdes. Los metagabros representan la actividad magmática tholeítica y presentan texturas de emplazamiento y enfriamiento en condiciones de poca profundidad. Esta litología se encuentra afectada por un grado metamórfico más alto. Las texturas y estructuras preservadas en las rocas volcánicas máficas indican una importante erupción submarina. Esto estaría avalado por la importante cantidad de hialoclastitas máficas, acidas y brechas. Posibles estructuras en lavas almohadilladas han sido reconocidas en un solo lugar y seguramente se deba a que las mismas han sido obliteradas por la deformación y el metamorfismo. Las brechas suelen ser relativamente comunes a profundidades relativamente bajas (menores a los 100 metros) es un argumento más a favor de que los depósitos sedimentarios que constituyen el Grupo Lavalleja, fueron sedimentados en parte a baja profundidad y con importantes variaciones del nivel del mar asociado a una actividad tectónica importante. La sucesión sedimentaria, interestratificada con la unidad volcánica, se encuentra constituida por importantes niveles detríticos -tales como potentes niveles pelíticos y psamíticos-, calcoclásticos y carbonáticos. Los niveles conglomerádicos suelen ser escasos y poco potentes. La asociación de las distintas litofacies hace pensar en ambiente marino de aguas someras en una cuenca que ha pasado por momentos de estabilidad como de inestabilidad tectónica. Asimismo, metagabros y niveles de chert intercalados en bancos pelíticos ubicados inmediatamente al oeste de la ruta 60, a la altura de la localidad de Nueva Carrara han sido señalados por Pena et al. (1987a y b). Aunque no ha sido corroborada la presencia de éstos niveles de chert podría, esta asociación llegar a interpretarse como la parte más profunda de la cuenca donde las pelitas pelágicas con intercalaciones de chert son comunes. Klein (1985) -a partir de los resultados del proyecto de perforación del fondo oceánico (Deep Sea Drilling Project and the Ocean Drilling Programy, DSDP)-, nueve tipos de sedimentación en el núcleo de las cuencas de trasarco: flujos de detritos (debrisflows), sistemas depositacionales de abanicos submarinos, turbiditas (silty basinal turbidites), pelitas hemipelágicas (hemipelagic clays), pelitas pelágicas (pelagic clays), sedimentos pelágicos silico-biogénicos, carbonates pelágicos biogénicos, carbonates resedimentados y piroclastitas. Este mismo autor sugirió que la distribución de las facies en una cuenca de trasarco es comúnmente independiente del tiempo o de los procesos tectónicos. Importantes procesos afectan la composición y distribución de los sedimentos dentro de una cuenca de trasarco, tales como la circulación de las corrientes oceánicas, controles latitudinales en la productividad biogénica y la depositación (carbonates versus sílice) y la energía de los sedimentos desde las grandes masas continentales (por ej. pelitas hemipelágicas). Por otra parte Alien \& Alien (1992) sugirió que los ambientes depositacionales de las cuencas de trasarco desarrolladas sobre corteza oceánica son marino profundo, excepto a lo largo de sus márgenes donde pueden existir depósitos fluviales, costeros y someros. A partir del hallazgo de las trazas fósiles en la sucesión sedimentaria del Grupo Lavalleja (Aceñolaza et al. 1998) quedaría acotada la edad máxima del mismo en circa 700-750 $\mathrm{Ma}$, mientras que, a partir de los estudios radimétricos aportados por (Sánchez Bettucci \& Linares 1996,1997, Linares \& Sánchez Bettucci 1997) que señalan el inicio del magmatismo del Complejo Sierra de Las Animas circa $615 \mathrm{Ma}$, se deduce que tanto el magmatismo y la sedimentación del grupo Lavalleja debió haber ocurrido en el lapso entre los 750 y los $615 \mathrm{Ma}$. Las paragénesis metamórficas están indicando un metamorfismo de tipo regional de baja presión a moderadas, aumentando paulatinamente en dirección oeste a este. En muchos niveles metasedimentarios las texturas y estructuras primarias se encuentran preservadas. A partir de la interpretación de los datos de campo, petrográficos y geoquímicos (Sánchez Bettucci 1998) se propone que estas unidades podrían estar representando depósitos de cuenca de trasarco (back are basin), situada entre el bloque Florida, al oeste, y un arco magmático representado por el Complejo Carapé hacia el este. Este ultimo estaría representado por los granitos pre a postectónicos, que varían desde cuarzo-dioritas hasta granitos con naturaleza calcoalcalina a subalcalina. Esta asociación estaría representando niveles corticales profundos.

Agradecimientos Al Consejo Sectorial de Investigaciones Científicas, proyecto CSIC-078 por el apoyo financiero. Se agradece además a los revisores anónimos por su importante ayuda en el mejoramiento del manuscrito.

\section{Referencias}

Aceñolaza G.F., Sánchez Bettucci L., Fernicola J.C. 1998. Presencia de trazas fósiles en la sucesión sedimentaria del Grupo Lavalleja, Uruguay. Coloquios de Paleontología, 49:9-21

Alien P.A. \& Aallen J.R. 1992. Basin Analysis: Principies and applications. Blackwell Scientific Publications, Oxford, 450pag.

Bossi J. \& Campal N. 1992. Magmatismo y tectónica transcurrente durante el Paleozoico inferior del Uruguay. In: J. Gutiérrez, J. Saavedra, \& I. Rábano (Eds.) Paleozoico Inferior de Ibero-América, pp. 343-356, Universidad de Extremadura, Alicante.

Bossi J. \& Navarro R. 1991. Geología del Uruguay. L. Departamento de Publicaciones de la Universidad de la República, Montevideo, $453 \mathrm{pp}$.

Bossi J. 1989. Recientes avances sobre la Geología del Cinturón Orogénico Moderno (1000-500 Ma) en Uruguay. Boletín de Investigaciones de la Facultad de Agronomía, 20:1-24.

Bucher K. \& Frey M. 1994. Petrogenesis ofmetamorphicRocks. Springer-Verlag, Berlin, 328 pág.

Chiron J.J. 1982. Inventario Minero del Uruguay. Primera fase-informe final. BRGM-Dirección Nacional de Minería y Geología. Informe Técnico, 79 pág. (inédito)

Cosarinsky M. 1997. Geología del sector sur de la región Fuente del Puma, Departamento de Lavalleja, Uruguay. Tesis de Licenciatura, Universidad de Buenos Aires, Buenos Aires, 151 pág

Dick H.J.B. 1982. The petrology of two back-arc basins of the nortern North Philippine Sea. Am. J. Se., 282: 644-700
Fernandos L.A.D., Menegat R., Uberti Costa A.F., Koester E., Porcher C.C., Tommasi A. Kraemer G., Rambgrab G.E., Camozzato E. 1995a. Evolufao Tectónica do Cinturao Dom Feliciano no escudo Sul-Rio-Grandense: Parte I - Urna contribucao a partir do registro Geológico. Rev. Bras. Geoc., 25:351-374.

Fernandes L.A.D., Menegat R., Uberti Costa A.F., Koester E., Porcher C.C., Tommasi A., Kraemer G., Rambgrab G.E., Camozzato E. 1995b. Evolucao Tectónica do Cinturao Dom Feliciano no escudo Sul-Rio-Grandense: Parte II - Urna contribucao a partir das assinaturas Geofisicas. Rev. Bras. Geoc., 25:351-374.

Fernandes L.A.D., Tommasi A., Porcher C.C. 1992. Deformation patterns in the southern Brazilian branch of the Dom Feliciano Belt: A reapprisal. Jour. South Am. Earth Sciences, 5:77-96.

Fernandes L.A.D., Tommasi A., Porcher C.C., Vauchez A. 1993. Zonas de cizalhamento transcorrentes do Cinturao Dom Feliciano: Caracterizaçao e importancia tectónica. In: Simposio Internacional del Neoproterozoico-Cámbrico de la Cuenca del Plata, 1: 137-141, La Paloma.

Fragoso Cesar A. R .S. 1993. As Placas Brasilianas do sul e sudeste da Plataforma Sul Americana. In: IV simposio Nacional de Estudos Tectónicos, 12: 183-188, Belo Horizonte.

Fragoso Cesar A. R. S. 1995. The Neoproterozoic Brazilides collage in the Southern South American Platform. In: VI Simposio Nacional de Estudos Tectónicos, 12:183-188, Curitiba. 
Fragoso Cesar A R S, Machado R, Phillip > R, Mello F. Endo I, Nummer A, Preciozzi F., Frambini G., Sayeg H. 1998. Terrenos suspeitos ao sul da Placa Sanfranciscana (se da Plataforma Sul-Amerícana). Actas del II Congreso Uruguayo de Geología Punta del Este, Uruguay,. P. 1 -6.

Fragoso Cesar A.R.S. \& Machado R. 1997. Neoproterozoic terranes of the Gaucho Shield (Southern Brazil and Uruguay). In: Southern American Symposium on Isotope Geology, 1: 65-67, San Pablo.

Fragoso Cesar A.R.S. 1980. O Cráton do rio de La Plata e o CinturSo Dom Feliciano no Escudo Uruguaio-Sul-Riograndense. In: Congreso Brasileiro de Geología, 31, 5:2879-2892, Camboriú.

Fragoso Cesar A.R.S. 1991. Tectónica de Placas no Ciclo Brasiliano: as Orogenias dos Cinturdes Dom Feliciano e Ribeira no Rio Grande do Sul. Tesis de Doctorado IG-Universidade Sao Paolo, San Pablo, 467 pág.

Gaucher C. \& Sprechmann P. 1995. Paleontología, Sedimentología y Paleogeografia del Proterozoico medio y superior del Terreno Nico Pérez. In: 6 Simposio Sul-Brasileiro de Geología, pp. 101-104, Porto Alegre.

Gaucher C., Sprechmann P., Shipilov A. 1996. Upperand Middle Proterozoic fossiliferous sedimentary sequences of the Nico Pérez Terrane of Uruguay: Liyhostratigraphic units, paleontology, depositional environments and correlations. Njb. Geol. Palaont. Abh., 199:339-367.

Gómez Rifas C. 1995. A zona de cisalhamento sinistral "Sierra Ballena" no Uruguai. Tesis de Doctorado, Universidade de Sao Paulo, San Pablo, 243 pág.

GrotzingerJ. P. 1989. Facies and Evolución ofPrecambrian carbonate depositional systems: emergence of the modem platform archetype. In: P.D. Crevello J.L. Wilson J.F. Sarg \& Read J.F. (Eds.), Controls on Carbonate Platform and Basin development. Society of Economic Paleontology and Mineralogists, 44:79-106.

Hartmann L.A., Silva L., Remus M., Leite J., Barboza Giménez N. 1998. Evolugao geotectónica do sul do Brasil e Uruguai entre 3,3 Ga E 470 Ma. Actas del II Congreso Uruguayo de Geología, Punta del Este, Uruguay, p.277-284.

Klein G. V. 1985. The control of depositional depth, tectonic uplift and volcanism on sedimentation processes in the back are basins of Western Pacific Ocean. Journal of Geology, 93:1-25.

Kornprobst J. 1996. Manual de Petrología metamórfica y su contexto geodinámica. Masson, Barcelona, 220 pág.

Linares E. \& Sánchez Bettucci L. 1997. Edades Rb/Sr y K/Ar del cerro Pan de Azúcar, Piriápolis, Uruguay. In: South American Symposium on Isotope Geology, 1:176-180, San Pablo.

Logan B. W., Rezak R. , Ginsburg R.N. 1964. Classification and environmental significance of alga stromatolites. Jour. Geology, 72:68-83

Machado R. \& Fraagoso Cesar A.R.S. 1987. Deformacoes brasilianas do cinturao Dom Feliciano no Uruguai. In: Simp.Sul-Bras.Geol., 3, 2:811-820, Curitiba.

Marstrander R. 1914. Los mármoles de Carapé. Boletín del Instituto de Geología y Perforaciones, 1:1-44.

McMillan J. 1933. Terrenos precámbricos del Uruguay. Boletín del Instituto Geológico del Uruguay, 18:1-60.

Midot D. 1984. Elude Géologique et Diagnostic Met allegénique pour l'Exploration du Sector de Minas (Uruguay). Tesis de Doctorado. Université de París IV, París, 175 Pág-

Miyashiro A. 1994. Metamorphic petrology. UCL Press, England, 404 pág.

Pena S., Masquelin H., Oyhantcabal P., Pías J., Tabo, F. 1987a. Estudio Geoló gico de la anomalía 270-01 "El Penitente". Dirección Nacional de Minería y Geología. Informe Técnico, 13 pág. (inédito)

Pena S., Masquelin H., Pias J., Tabo F., Oyhantcabal P. 1987b. Estudio Geológico de los alrededores de la Mina Apolonia. Dirección Nacional de Minería y Geología. Informe Técnico, 32 pág. (inédito)

Preciozzi F. \& Pena S. 1990. Memoria explicativa del Fotoplano Fuente del Puma, Escala 1/100.000. Dirección Nacional de Minería y Geología - Facultad de Agronomía -Facultad de Humanidades y Ciencias. Informe Técnico, 17 pág. (inédito).

Preciozzi F. 1989a. Lineas estructurales de la secuencia volcano-sedimentaria del Grupo Lavalleja (ciclo brasiliano): región Minas-Pan de Azúcar, Uruguay. Contribuciones a la Geología del Uruguay. Dirección Nacional de Minería y Geología 1. Informe Técnico, 17 pág. (inédito)
Preciozzi F. 1989b. Litoestratigrafía de la secuencia volcano-sedimentaria del Grupo Lavalleja (ciclo brasiliano): región Minas-Pan de Azúcar, Uruguay. Contribuciones a la Geología del Uruguay. Dirección Nacional de Minería y Geología 2. Informe Técnico, 24 Preciozzi F. 1989c. Características metalogenéticas de la secuencia volcano-sedimentaria del Grupo Lavalleja (ciclo brasiliano): región Minas-Pan de Azúcar, Uruguay. Contribuciones a la Geología del Uruguay, Dirección Nacional de Minería y Geología 3: Informe Técnico, 15 pág. (inédito).

Preciozzi F. 1989d. Características petrográficas y metamórficas de la secuencia volcano-sedimentaria del Grupo Lavalleja (ciclo brasiliano): región Minas-Pan de Azúcar, Uruguay. Contribuciones a la Geología del Uruguay 4. Dirección Nacional de Minería y Geología. Informe Técnico, 13 pág. (inédito)

Preciozzi F., Bossi J., Morales H. 1991. The Uruguayan cristalline basement. In: C. M., Podozis (Ed.), Global Geosciences Transect, Valparaíso, Chile - Punta del Este, Uruguay. UNESCO, París, 35 pág.

Preciozzi F., Masquelin H., Sanchos Bettucci L. 1993. Geología de la Porción sur del Cinturón Cuchilla de Dionisio. In: F. Preciozzi, H. Masquelin \& L. Sánchez Bettucci (Eds.), Guía de Excursión del Primer Simposio Internacional del Neoproterozoico-Cámbrico de la Cuenca del Plata. Dirección Nacional de Minería y Geología, p.1-39, Montevideo.

Preciozzi F., Spoturno J., Heinzen W., Rossi P. 1985a. Carta Geológica del Uruguay a escala 1:500.000, Dirección Nacional de Minería y Geología, Montevideo, 92 pág..

Sánchez Bettucci L. \& Uñares E. 1996. Primeras edades en basaltos del Complejo Sierra de Animas, Uruguay. In: XII Congreso Geológico Argentino y III Congreso de Exploración de Hidrocarburos, 1: 399-404, Buenos Aires.

Sánchez Bettucci L. \& Linares E. 1997. The geochronologic scheme of the eruptive rocks in the Piriápolis sheet, Uruguay. In: South American Symposium on Isotope Geology I: 49-53, Sao Paulo.

Sánchez Bettucci L. 1998. Evolución tectónica del Cinturón Dom Feliciano en la región Minas-Piriápolis, Uruguay. Tesis de Doctorado, Universidad de Buenos Aires, 344 pp.

Sanches Bettucci L. Cosarinsky M., Page S. 1997. Un posible trasarco proterozoico para el sudeste del Uruguay: fundamentos estratigráficos y geoquímicos. In: VIII Congreso Geológico Chileno 2:1528-1532, Antofagasta.

Saunders A.D. \& Tarney J. 1979. The Geochemestry of basalts from back-arc spreading centre in the East Scotia Sea. Goechim. Cosmochim. Acta, 43:555-572.

Saunders A.D. \& Tarney J. 1991. Back-arc basins. In: P.A. Floyd (Ed.), Oceanic Basalts, Blackie, Van Nostrand, Reinhold, Glasgwow, pp. 219-263.

Spoturno J., Coronel N., Da Silva J. 1986. Geología y Prospección fosfático-uranífera: "Área La Calera". Boletín de la Dirección Nacional de Minería y Geología, 39:7-29.

Sun S.S. 1982. Chemical composition and origin of the Earth's primitive mande. Geoch. Cosmoch. Acta, 46:179-192.

Visher G. S. 1965. Use of a vertical profile in envirnonment reconstruction. Am. Ass. Petr. Geol. Bull., 49:41-64.

Walther K. 1912. Sobre los yacimientos geológicos de valor técnico en la República Oriental del Uruguay. Revista del Instituto Nacional de Agronomía de Montevideo, $1: 37-47$.

Walther K,. 1919. Lineas fundamentales de la Estructura Geológica de la República Oriental del Uruguay. Revista del Instituto Nacional de Agronomía, (2a Serie) 3:3-67.

Wilson J.T. 1975. Carbonate Facies in Geologic History. Springer, Berlín, 471 pág.

Yardley B.W.D. 1988. An introduction to metamorphic petrology. Longman, Harlow, 248 